\title{
Protein gradients on the nucleoid position the carbon-fixing organelles of cyanobacteria
}

\section{Joshua S MacCready ${ }^{1}$, Pusparanee Hakim ${ }^{2}$, Eric J Young ${ }^{3}$, Longhua $\mathrm{Hu}^{4}$, Jian $\mathrm{Liu}^{4}$, Katherine W Osteryoung ${ }^{5}$, Anthony G Vecchiarelli ${ }^{2 *}$, Daniel C Ducat ${ }^{3,6 *}$}

${ }^{1}$ Department of Microbiology and Molecular Genetics, Michigan State University, East Lansing, United States; ${ }^{2}$ Department of Molecular, Cellular, and Developmental Biology, University of Michigan, Michigan, United States; ${ }^{3}$ Department of Biochemistry, Michigan State University, East Lansing, United States; ${ }^{4}$ Biochemistry and Biophysics Center, National Heart, Lung, and Blood Institute, National Institutes of Health, Bethesda, United States; ${ }^{5}$ Department of Plant Biology, Michigan State University, East Lansing, United States; ${ }^{6} \mathrm{MSU}-\mathrm{DOE}$ Plant Research Laboratory, Michigan State University, East Lansing, United States

Abstract Carboxysomes are protein-based bacterial organelles encapsulating key enzymes of the Calvin-Benson-Bassham cycle. Previous work has implicated a ParA-like protein (hereafter McdA) as important for spatially organizing carboxysomes along the longitudinal axis of the model cyanobacterium Synechococcus elongatus PCC 7942. Yet, how self-organization of McdA emerges and contributes to carboxysome positioning is unknown. Here, we identify a small protein, termed $\mathrm{McdB}$ that localizes to carboxysomes and drives emergent oscillatory patterning of McdA on the nucleoid. Our results demonstrate that McdB directly stimulates McdA ATPase activity and its release from DNA, driving carboxysome-dependent depletion of McdA locally on the nucleoid and promoting directed motion of carboxysomes towards increased concentrations of McdA. We propose that McdA and McdB are a previously unknown class of self-organizing proteins that utilize a Brownian-ratchet mechanism to position carboxysomes in cyanobacteria, rather than a cytoskeletal system. These results have broader implications for understanding spatial organization of protein mega-complexes and organelles in bacteria.

DOI: https://doi.org/10.7554/eLife.39723.001

\section{Introduction}

Bacterial microcompartments (BMCs) are protein-based organelles that encapsulate specialized metabolic processes in $20 \%$ of all sequenced bacteria (Axen et al., 2014). Over 23 different classes of $\mathrm{BMC}$ are broadly distributed across bacterial phyla, but perhaps the best characterized class are the large $(\sim 175 \mathrm{~nm})$ carbon-fixing carboxysomes of cyanobacteria (reviewed here: Rae et alo, 2013; Kerfeld and Melnicki, 2016). Carboxysomes encapsulate the key Calvin-Benson-Bassham cycle enzyme, ribulose-1,5-bisphosphate carboxylase/oxygenase (RuBisCO), and enhance the carbon fixation efficiency of this enzyme by creating a microenvironment that is enriched for $\mathrm{CO}_{2}$. Specifically, carboxysomes consist of an outer 'shell' layer that encapsulates both RuBisCO and carbonic anhydrase: the localized conversion of bicarbonate to $\mathrm{CO}_{2}$ near RuBisCO is thought to greatly reduce its oxygenase activity, thereby suppressing the energetically-costly process of photorespiration (Rae et al., 2013). In the model rod-shaped cyanobacterium Synechococcus elongatus PCC 7942 (hereafter S. elongatus), it has been shown that carboxysomes align along the longitudinal axis of the cell (Savage et alo, 2010). This equidistant positioning is thought to promote equal inheritance 
eLife digest Cyanobacteria are tiny organisms that can harness the energy of the sun to power their cells. Many of the tools required for this complex photosynthetic process are packaged into small compartments inside the cell, the carboxysomes. In Synechococcus elongatus, a cyanobacterium that is shaped like a rod, the carboxysomes are positioned at regular intervals along the length of the cell. This ensures that, when the bacterium splits itself in half to reproduce, both daughter cells have the same number of carboxysomes.

Researchers know that, in S. elongatus, a protein called McdA can oscillate from one end of the cell to the other. This protein is responsible for the carboxysomes being in the right place, and some scientists believe that it helps to create an internal skeleton that anchors and drags the compartments into position.

Here, MacCready et al. propose another mechanism and, by combining various approaches, identify a new partner for McdA. This protein, called $M c d B$, is present on the carboxysomes. McdB also binds to McdA, which itself attaches to the nucleoid - the region in the cell that contains the DNA. McdB forces McdA to release itself from DNA, causing the protein to reposition itself along the nucleoid. Because McdB attaches to McdA, the carboxysomes then follow suit, constantly seeking the highest concentrations of McdA bound to nearby DNA. Instead of relying on a cellular skeleton, these two proteins can organize themselves on their own using the nucleoid as a scaffold; in turn, they distribute carboxysomes evenly along the length of a cell.

Plants also obtain their energy from the sun via photosynthesis, but they do not carry carboxysomes. Scientists have tried to introduce these compartments inside plant cells, hoping that it could generate crops with higher yields. Knowing how carboxysomes are organized so they can be passed down from one generation to the next could be important for these experiments.

DOI: https://doi.org/10.7554/eLife.39723.002

of carboxysomes to both daughters of a dividing cell, which has been shown to impact cyanobacterial fitness under ambient $\mathrm{CO}_{2}$ (Savage et al., 2010; Rae et al., 2013; Kerfeld and Melnicki, 2016). Since cyanobacteria contribute to greater than $25 \%$ of global carbon-fixation, how carboxysome organization is maintained is of considerable ecological importance. However, the mechanisms used to position any BMC, including carboxysomes, has remained elusive.

The most comprehensive study of BMC positioning to date showed that a ParA-type ATPase (hereafter McdA - Maintenance of carboxysome distribution A) displayed oscillatory dynamics in $S$. elongatus and was required for proper positioning of carboxysomes (Savage et alo, 2010). ParA family members have been most comprehensively studied as factors important for the segregation of genetic material; bacterial chromosomes and low-copy plasmids (reviewed here: Baxter and Funnell, 2014). Early hypotheses of ParA function favored a cytoskeletal model in which ParA formed filaments that self-assemble into a larger scaffold capable of segregating genetic cargo, analogous to a primitive mitotic spindle (Ringgaard et al., 2009; Ptacin et al., 2010). These models were supported in part by in vitro observations of fibrous, long bundled filaments of purified members of the ParA/MinD family of proteins (Reviewed here: Vecchiarelli et alo, 2012). Such filament-based models, combined with the requirement of McdA for carboxysome positioning, led to the prevailing theory that carboxysomes (Savage et alo, 2010) and other BMCs (Parsons et al., 2010) could be tethered to a cryptic cytoskeletal element that traverses the cell length and/or exerts positioning forces.

More recently, filament-based models of ParA have been challenged by experiments utilizing reconstituted cell-free systems (Hwang et al., 2013; Vecchiarelli et al., 2013; Vecchiarelli et al., 2014), super-resolution microscopy (Le Gall et al., 2016; Lim et al., 2014), crystallography (Zhang and Schumacher, 2017), and mathematical modelling approaches (Hu et alo, 2015; Hu et al., 2017; Le Gall et al., 2016; Lim et al., 2014; Surovtsev et al., 2016). These new data are consistent with a model whereby asymmetric distributions of ParA dimers on the nucleoid drive directed and persistent movement of DNA cargos (e.g. plasmids) towards increased concentrations of ParA via a Brownian-ratchet mechanism that does not require a cytoskeletal element. ParA-mediated DNA segregation via this proposed mechanism requires only three factors: (i) a ParA-type 
ATPase that dimerizes and non-specifically binds the nucleoid in the presence of ATP (Leonard et al., 2005; Hester and Lutkenhaus, 2007; Castaing et al., 2008; Vecchiarelli et al., 2010), (ii) a partner protein, ParB, that site-specifically binds DNA and stimulates the ATPase activity of ParA to displace it from the nucleoid (Davis et al., 1992; Bouet and Funnell, 1999; Bouet et al., 2000), and (iii) a centromere-like site on the DNA cargo (parS) that ParB loads onto (Davis and Austin, 1988; Funnell, 1988). In this model, multiple dimers of ParB form a large protein-DNA complex around the parS site, which leads to a break in ParA symmetry across the nucleoid due to the formation of local ParA depletion zones around individual ParB-bound cargos (Adachi et al., 2006; Hatano et al., 2007; Hwang et al., 2013; Vecchiarelli et al., 2014). In turn, transient ParA-ParB interactions could translate the asymmetrical distribution of ParA across the nucleoid into a directional cue for processive motion of cargo towards the highest local concentration of ParA.

Despite extensive research into carboxysome biogenesis and organization, as well as efforts to identify the full complement of proteins associated with many BMC classes, the only evidence for an underlying cytoskeletal-mode of BMC organization is indirect. Brownian ratchet-based models are gaining favor within the ParA field, but there is not yet a broad consensus and there is substantial uncertainty as to whether ParA-type ATPases form functional filaments in vivo (Wagstaff and Löwe, 2018). Additionally, no factors suitable to play a role analogous to ParB or parS have been identified for McdA, preventing any direct assessment of a putative Brownian ratchet-based mechanism for carboxysomal organization. Therefore, whether McdA acts as part of a ParA-like system or utilizes a unique mechanism has remained an open question. Indeed, several fundamental questions remain unanswered in relation to carboxysome positioning, including: (i) Does McdA form a cytoskeletal structure or follow a Brownian-ratchet mechanism? (ii) Upon what cellular surface does McdA bind in order to processively oscillate from pole-to-pole? (iii) What factors contribute to the emergence of higher-order McdA patterning? (iv) How do oscillations of McdA contribute to carboxysome distribution?

Here, we identify a novel factor, we term McdB (Maintenance of carboxysome distribution protein B) that localizes to carboxysomes via interaction with outer shell proteins and regulates carboxysome positioning within the cytosol. While McdB has no identifiable similarities with any known ParB-family members, we find that $\mathrm{McdB}$ can directly interact with McdA to stimulate its ATPase activity and release it from DNA in vitro, and promote its pole-to-pole oscillation in vivo. Changes in McdB expression resulted in loss of McdA oscillatory dynamics, loss of equidistant carboxysome positioning and alteration of carboxysome ultrastructure. Although several features of McdAB differ significantly from those of classic ParAB family members, we find that a Brownian ratchet model of localized concentration gradients of McdA on the nucleoid is consistent with our results and may also reconcile past observations of carboxysome positioning. We discuss our results in light of their implications for BMC positioning and biogenesis, as well as the insights that this carboxysome positioning system can provide for a broader class of self-organizing proteins including the ParAB family.

\section{Results}

\section{McdA dynamically patterns along the nucleoid}

In the DNA partition process, ParA-type ATPases successively bind ATP, dimerize, and bind non-specifically to DNA (Leonard et alı, 2005; Hester and Lutkenhaus, 2007; Castaing et alı, 2008; Vecchiarelli et al., 2010). In vivo, this mechanism establishes the nucleoid as the biological surface upon which directed DNA cargo motion occurs (Hatano and Niki, 2010; Sengupta et al., 2010; Castaing et al., 2008; Le Gall et al., 2016). In the model rod-shaped cyanobacterium S. elongatus, the ParA-like protein we call McdA (Synpcc7942_1833; Maintenance of carboxysome distribution protein $\underline{A}$ ) is required for positioning carboxysomes via an unknown oscillatory mechanism (Savage et al., 2010). However, the ParA family of ATPases contains MinD proteins, which bind membranes, ParA proteins, which bind DNA, and McdA has been broadly hypothesized to form filaments. Therefore, it remained unclear if McdA uses a biological surface to self-organize in the cell or if it forms a free-standing cytoskeletal network as previously proposed (Savage et al., 2010).

Since a C-terminal GFP fusion of McdA was previously used to observe McdA oscillation and its involvement in carboxysome positioning in vivo (Savage et alı, 2010), we purified McdA-GFP-His and examined its capacity to bind DNA via an Electrophoretic Mobility Shift Assay (EMSA). We 
observed that McdA-GFP-His significantly shifted non-specific DNA (nsDNA) in the presence of ATP (Figure 1A). To more directly examine the interaction of McdA with DNA, we used Total Internal Reflection Fluorescence Microscopy (TIRFM) to visualize McdA-GFP-His dynamics upon a DNAcoated surface; a technique that also has sufficient resolution to resolve oligomeric McdA filaments proposed to be involved in carboxysome positioning (Savage et al., 2010; Yokoo et al., 2015). A flowcell unit was decorated with nsDNA fragments ( 500 bp sonicated salmon sperm DNA) at high density $\left(\sim 1000\right.$ fragments $\left./ \mu^{2}\right)$ (Vecchiarelli et alo, 2013) to create a visualizable DNA-coated surface. Consistent with EMSA analysis, McdA-GFP-His uniformly bound the DNA carpet when infused into the flowcell with ATP, (Figure 1B and Video 1), but showed no appreciable DNA binding when ADP or ATP- $\gamma$-S were added, or when nucleotides were omitted (Figure 1C). No McdA filaments were observed forming under any of these conditions (Video 1).

We then sought to examine endogenous localization and dynamics of McdA, therefore we gener-

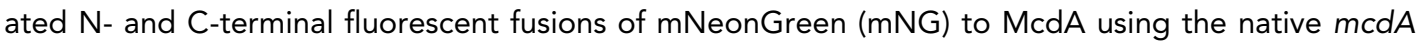
promoter and chromosomal location. Interestingly, our native $\mathrm{C}$-terminally tagged reporter (McdA$\mathrm{mNG}$ ) did not show dynamic oscillations and instead formed a uniform distribution of signal along the longitudinal axis ( $\geq 99 \%$ of cells; $n=950$ cells) (Figure 1D, Figure 1-figure supplement $1 \mathrm{~A}$ and Table 1.). Alternatively, an $\mathrm{N}$-terminally tagged reporter (mNG-McdA) displayed robust oscillations ( $\geq 99 \%$ of cells; $n=442$ cells) (periodicity of 15.3 min per $3.3 \mu \mathrm{m}, \sim 5-6 \times$ faster than

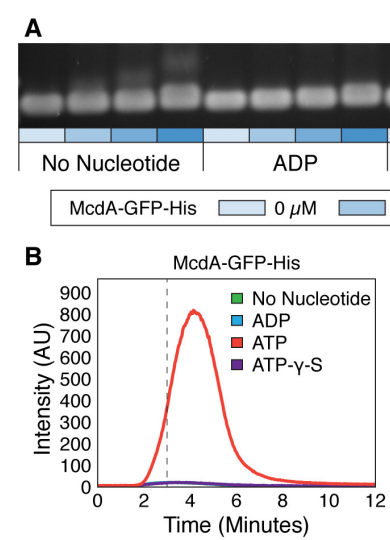

McdA-mNG

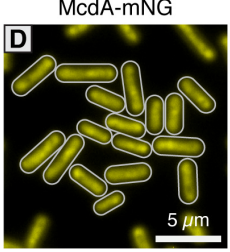

$\mathrm{mNG}-\mathrm{McdA}$

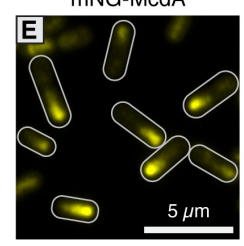

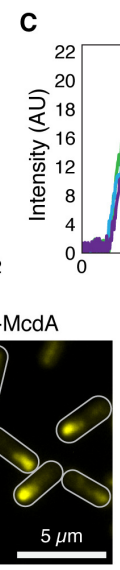
McdA-GFP-His McdA-GFP-His $\square$ No Nucleotide $\square$ ADP - ATP-Y-S $\begin{array}{cccc}6 & 8 & 10 & 12\end{array}$

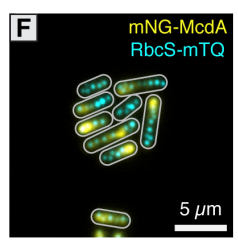

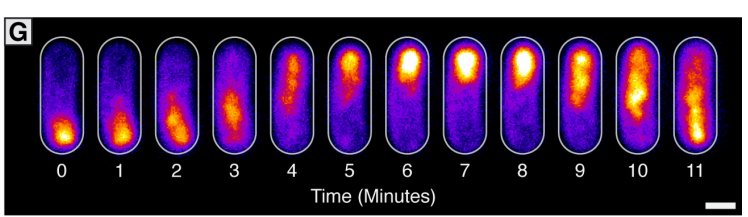

$\mathbf{H}$ DAPI Merged

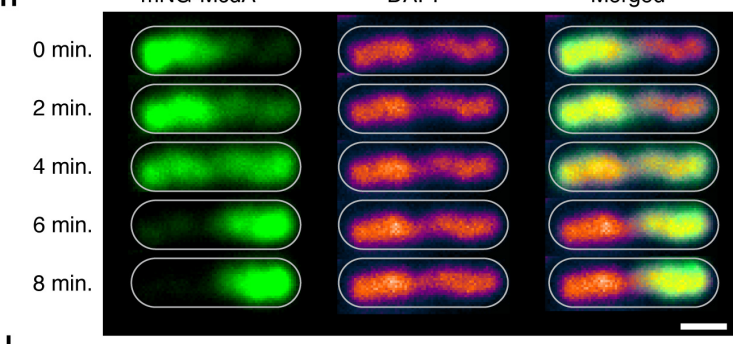

I

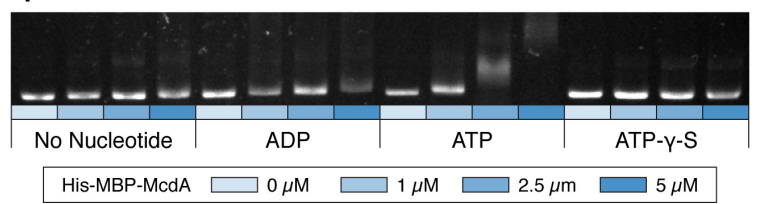

Figure 1. The ParA-like protein, McdA, binds nonspecifically to nucleoid DNA in the presence of ATP. (A) Purified McdA-GFP-His slows the migration of DNA in an ATP-dependent manner in an electrophoretic mobility shift assay (EMSA). (B) In flow cell experiments containing a carpet of non-specific DNA, McdA-GFP-His is preferentially retained by binding the DNA-carpet only in the presence of ATP, and releases when switching to a wash buffer after 3 min. (C) Magnified version of Panel B to show no protein binding without ATP. See Video 1. (D) Native McdA-mNG does not oscillate, while the $\mathrm{N}$-terminally tagged variant $(\mathrm{E})$ native $\mathrm{mNG}-\mathrm{McdA}$ displays robust oscillations in S. elongatus. $(\mathrm{F}) \mathrm{mNG}$-McdA (yellow) oscillates to position carboxysomes (RbcS-mTQ - cyan). (G) mNG-McdA waves concentrate predominantly along the central axis of the cell, and do not concentrate at the periphery near the cell membrane. Scale bar $=1 \mu \mathrm{m}$. (H) Oscillation of $\mathrm{mNG}-\mathrm{Mcd}$ A colocalizes with DAPI staining of nucleoid DNA, which is also centrally localized and is excluded from peripheral thylakoid membranes. Scale bar $=1 \mu \mathrm{m}$. (I) Purified His-MBP-McdA slows the migration of DNA in an ATP-dependent manner in an EMSA.

DOI: https://doi.org/10.7554/eLife.39723.003

The following source data and figure supplements are available for figure 1:

Figure supplement 1. $\mathrm{mNG}-\mathrm{McdA}$ oscillates and $\mathrm{mNG}-\mathrm{McdB}$ is recruited to carboxysomes.

DOI: https://doi.org/10.7554/eLife.39723.004

Figure supplement 1-source data 1. Source data for panel C.

DOI: https://doi.org/10.7554/eLife.39723.005 


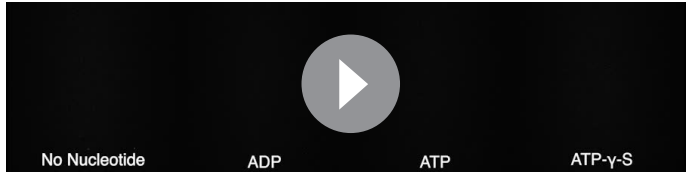

Video 1. McdA binds DNA only in the presence of ATP. After $3 \mathrm{~min}$, a wash buffer is flowed in.

DOI: https://doi.org/10.7554/eLife.39723.006

previously reported using McdA-GFP [Savage et al., 2010]) that formed a bimodal distribution of signal intensity (Figure 1EG, Figure 1-figure supplement $1 B$ and Video 2).

A carboxysome reporter was then generated by insertion of an additional copy of the small subunit of RuBisCO (RbcS) fused at the C-terminus to mTurquoise2 (mTQ) and expressed using a second copy of the native rbcS promoter. In this line, an average of 2 carboxysomes per micron of cell length was observed (Figure 1-figure sup-

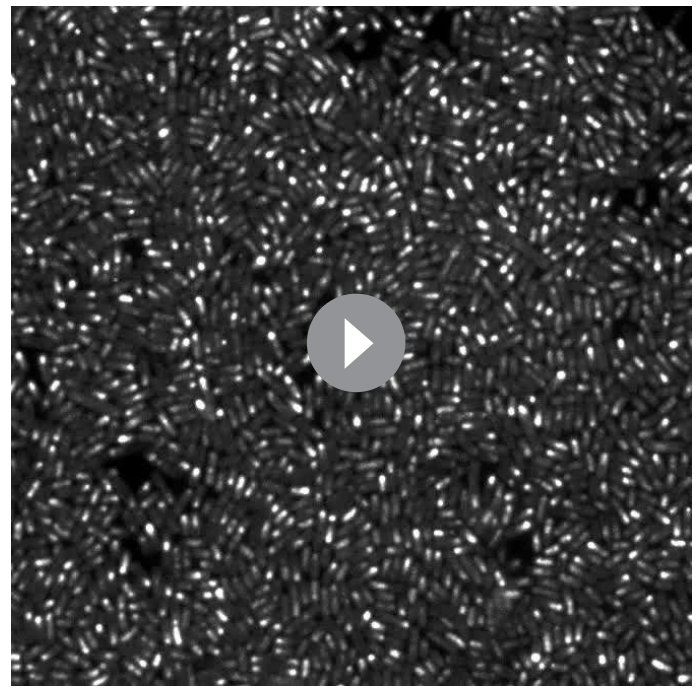

Video 2. Oscillation of mNG-McdA is observed across a population of cells.

DOl: https://doi.org/10.7554/eLife.39723.007 plement 1C). Cells bearing the mNG-McdA construct maintained carboxysome positioning along the longitudinal axis ( $\geq 99 \%$ of cells; $n=374$ cells) (Figure 1F, Figure 1-figure supplement 1D and Video 3), indicating the N-terminal fusion fully complemented McdA's known functions. To assay in vivo whether $\mathrm{mNG}-\mathrm{McdA}$ could be binding the nucleoid, we stained the cyanobacterial nucleoid with 4',6-Diamidine-2'-phenylindole dihydrochloride (DAPI) and recorded the mNG-McdA signal as it traversed the length of the cell. We found that the topology of the mNG-McdA signal closely resembled that of the DAPI-stained nucleoid (Figure 1H), providing additional evidence that the nucleoid is the surface upon which McdA dynamics are occurring. Since an N-terminal fusion of McdA was more functional in vivo, we performed an EMSA with an N-terminal fusion of McdA. While we found that wild-type McdA and His-mNG-McdA were insoluble and prone to degradation, an N-terminal fusion of McdA to Maltose Binding Protein (MBP) (His-MBP-McdA) was highly soluble. Consistent with our McdA-GFP-His EMSA, His-MBP-McdA shifted nsDNA in an ATP-dependent manner (Figure 1I). Together, our results demonstrate that ATP-bound N- or C-terminally tagged McdA binds DNA and McdA-GFP-His does not display indications of polymer formation at the resolution limits of our microscope.

\section{A previously uncharacterized protein is essential for emergent McdA dynamics}

Traditional ParA-family members require cognate ParB proteins to stimulate their ATPase activity and promote oscillatory dynamics. Yet no ParBlike ortholog has been identified for McdA. Although no obvious chromosomally-encoded homolog of parB could be detected in S. elongatus, we identified a parB-like gene (Synpcc7942_B2626) on the large plasmid (pANL) (Figure 2A). However, deletion of pANL parB did not disrupt oscillation of mNG-McdA ( $\geq 99 \%$ of cells; $n=554$ cells) (Figure $2 B$ and Figure $1-$

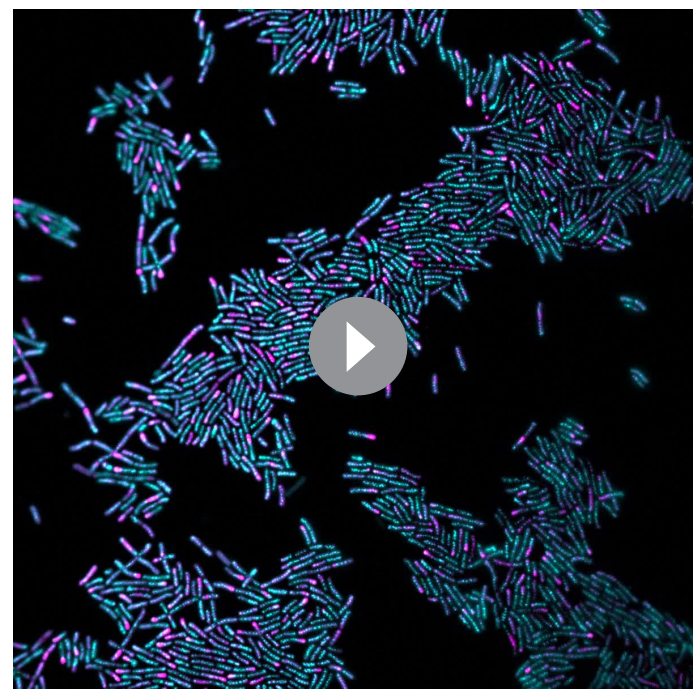

Video 3. Oscillation of mNG-McdA (magenta) occurs while carboxysomes (blue) are fluorescently labeled. DOI: https://doi.org/10.7554/eLife.39723.008 
figure supplement 1E). Two additional hypothetical genes were then selected due to their proximity to the mcdA gene, Synpcc7942_1834 and Synpcc7942_1835 (Figure 2A). While deletion of Synpcc7942_1835 had no observable effect on mNG-McdA oscillation ( $\geq 99 \%$ of cells; $n=834$ cells) (Figure 2C and Figure 1-figure supplement 1F), deletion of Synpcc7942_1834 resulted in complete loss of $m$ NG-McdA dynamics ( $\geq 99 \%$ of cells; $n=373$ cells). In the $\Delta$ Synpcc7942_1834 background, mNG-McdA concentrated in the center of the cell in the vicinity of the nucleoid, but without any consistent asymmetrical patterning (Figure 2D and Figure 1-figure supplement 1G). To more descriptively designate the activities we observe for Synpcc7942_1834 in this work, we will hereafter refer to this gene as maintenance of carboxysome distribution $\underline{B}(\mathrm{mcdB})$.

Bioinformatic analysis of the McdB protein by BlastP (protein-protein blast) revealed that McdB lacked homology to any known ParB family member, nor any identifiable conserved regions with known ParB proteins. We therefore used the jPred4 platform (Drozdetskiy et al., 2015) to analyze this $17 \mathrm{kDa}$ protein, which predicted that $\mathrm{McdB}$ possesses a secondary structure consisting mainly of alpha-helices, a highly charged $\mathrm{N}$-terminal $\mathrm{a}_{1}$-helix, and a coiled-coil C-terminal as-helix (Figure 2E). Because $\mathrm{McdB}$ appears to be a novel protein and there are no characterized proteins with comparable sequence, Phyre2 (Kelley et al., 2015) was unable to generate a reliable protein homology model.

We sought to determine if $\mathrm{McdA}$ and $\mathrm{McdB}$ directly interact by performing a bacterial two-hybrid assay (B2H) between $\mathrm{N}$ - and $\mathrm{C}$-terminally tagged McdA and McdB (Figure 2F). McdA and McdB were able to self-associate in the $\mathrm{B} 2 \mathrm{H}$ analysis. Self-association of $\mathrm{C}$-terminally tagged McdA proteins was faint, but confirmed on X-gal plates (Figure 2-figure supplement 1A). We also observed a reciprocal interaction between $\mathrm{N}$-terminally tagged $\mathrm{McdA}$ and $\mathrm{N}$-terminally tagged $\mathrm{McdB}$ (Figure 2F). However, C-terminally tagged McdB failed to show an interaction with McdA, while $\mathrm{C}$-terminally tagged $\mathrm{McdA}$ association with $\mathrm{McdB}$ was dependent upon expression conditions. These results suggest that $\mathrm{N}$-terminally tagged $\mathrm{McdA}$ only interacts with $\mathrm{N}$-terminally tagged $\mathrm{McdB}$, while $\mathrm{C}$-terminal fusions of either protein partially disrupts function, consistent with our in vivo observation of $\mathrm{mNG}-M c d A$ dynamics in comparison to McdA-mNG (Figure 1DE).

The ParA/MinD family of ATPases are defined by the presence of two lysine residues within their deviant Walker-A motif (KGGXXGKT) required for dimerization, ATP-binding, and ATP hydrolysis (Lutkenhaus, 2012). Interestingly, S. elongatus McdA lacks the signature amino terminal lysine residue (Figure 2G), suggesting that McdA might have an activity uncharacteristic of proteins from this family. Therefore, we set out to determine if McdA displayed ATPase activity. His-MBP-McdA displayed strong ATPase activity alone, significantly higher ( $>200$ fold) than that of traditional ParA family ATPases SopA of F plasmid and ParA of P1 plasmid (Figure 2G and Figure 2-figure supplement 1B). Because the ATPase activity was uncharacteristically high, we confirmed that the measured ATPase activity co-eluted with His-MBP-McdA from a size exclusion chromatography column and could not be attributed to a contaminating protein (Figure 2-figure supplement 1C). Relative to the constant specific activity of $F$ SopA-His and P1 ParA with increasing protein concentrations (Figure 2-figure supplement 1D), the specific ATPase activity of His-MBP-McdA declined at higher protein concentrations (Figure 2-figure supplement 1E). This decrease in ATPase activity was not due to substrate limitation during the course of the in vitro assay, as ATP was provided in excess, but could be indicative of a regulatory mechanism or product inhibition that is not characteristic of traditional ParA family members.

ParB partners stimulate the ATPase activity of their cognate ParA synergistically with nsDNA (Davis et al., 1992; Bouet and Funnell, 1999; Bouet et al., 2000). ParB stimulation is suggested to be coupled to ParA depletion on the nucleoid in the vicinity of ParB-bound cargo, as ADP does not support ParA binding to nsDNA (Leonard et al., 2005; Hester and Lutkenhaus, 2007; Castaing et al., 2008; Vecchiarelli et al., 2010). We tested whether McdB-His could stimulate McdA ATPase activity, analogously to traditional ParB members. When adding only nsDNA or McdB-His to the reactions, we observed very mild stimulation of His-MBP-McdA ATPase activity (Figure 2H). When both nsDNA and McdB-His were added simultaneously, the ATPase activity of His-MBP-McdA was further stimulated (Figure 2H and Figure 2-figure supplement 1G). An alternative preparation of McdA which was tagged at the C-terminus with GFP also exhibited intrinsically high ATPase activity that could be stimulated with the addition of nsDNA (Figure 2-figure supplement 1F), but addition of McdB-His did not further increase ATPase activity, in agreement with our 
A

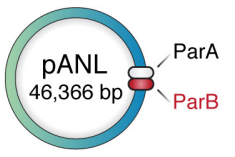

mNG-McdA $\triangle$ parB

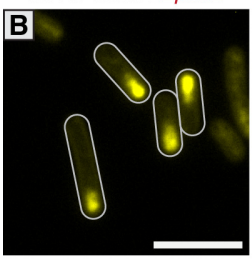

E

$\overbrace{\text { MTDAFDRLKKRSRTPIAREGSLTTGPELSDRPLQLLPREFETFCDRYAVHAGDVIEAALDLVL }}^{\alpha_{1}}$ LDPDLQRLLQRLRQGNGSDRVWLGTACPRSWQQQQQQAQDQGLSEADLLQEAIAQRLDLVL LDPDLQQRLLQRLRQGNGSDRVWLGTACPRSWQQQLQQQAQDQGLSEADLLQEAIAQRLDLV
$a_{8}$ GQTTLREEVTLLRQELDQLKRKLHGW
mNG-McdA $\triangle 1835$

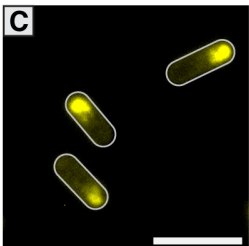

McdA Operon

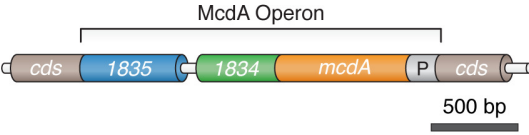

mNG-McdA $\triangle 1834$

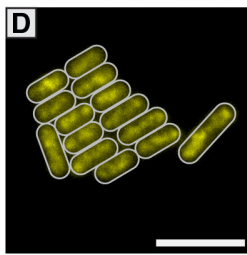

G

\begin{tabular}{|c|c|c|c|}
\hline & \multicolumn{3}{|c|}{ Specific Activity } \\
\hline & Walker-A Box & - DNA & + DNA \\
\hline His-MBP-McdA & $\ldots$ SGGQGKT . . & $14 \pm 8$ & $20 \pm 5$ \\
\hline SopA-His & .... KGGVYKT & $0.06 \pm 0.01$ & $0.09 \pm 0.02$ \\
\hline P1 ParA & $\ldots$ KGGVSKT . . . & $0.05 \pm 0.01$ & $0.09 \pm 0.01$ \\
\hline
\end{tabular}

H

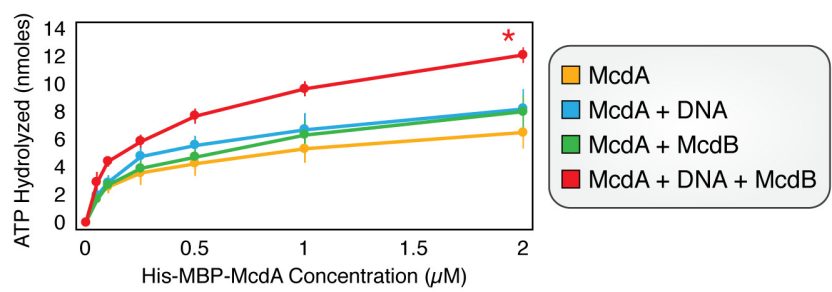

I

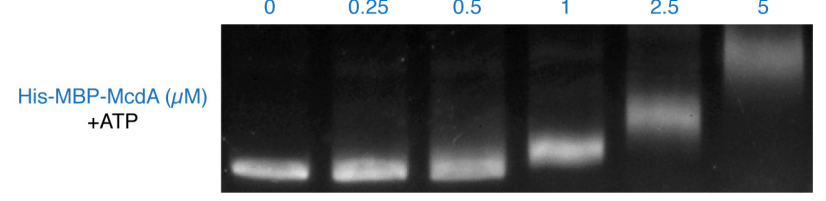

J

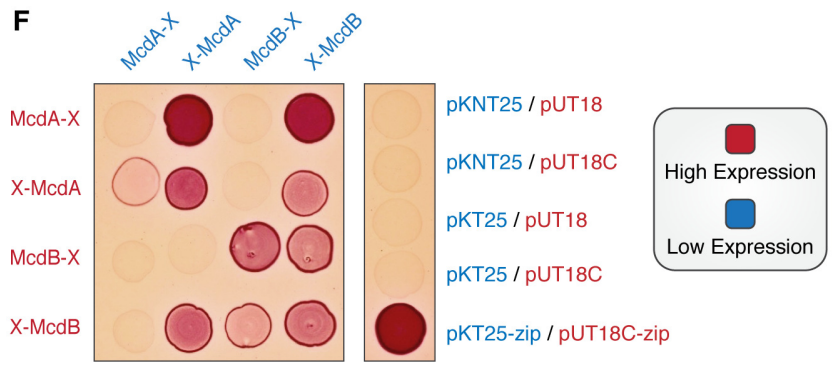

$2.5 \mu \mathrm{M}$ His-MBP-McdA + ATP + McdB-His $(\mu \mathrm{M})$

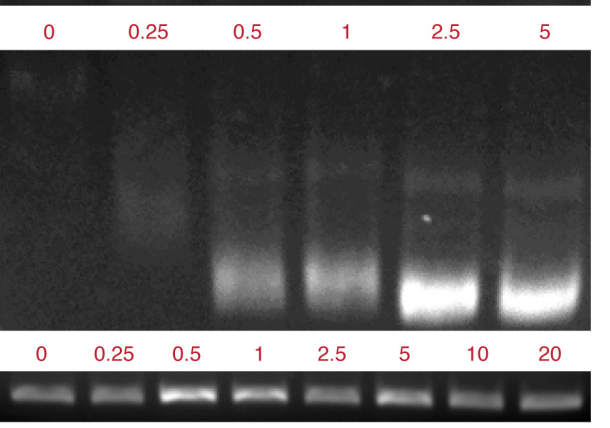

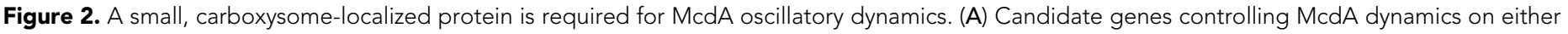

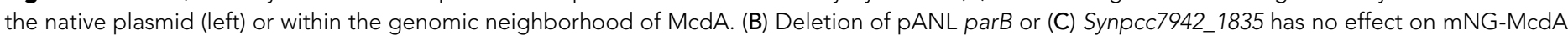

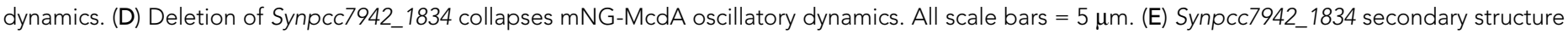
prediction: residues in red are predicted to form $\alpha$-helical secondary structure. (F) Bacterial two-hybrid between McdA and McdB tagged at their

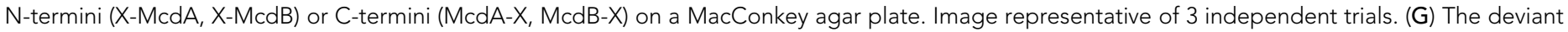

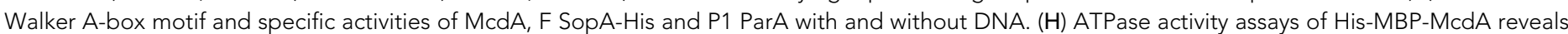
stimulatory roles of DNA and McdB-His. (I) His-MBP-McdA slows the migration of DNA in an ATP-dependent manner in an EMSA. (J) Increasing

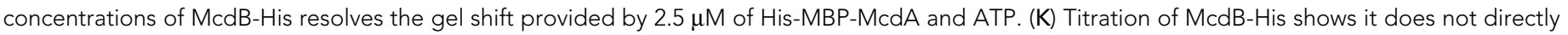
bind nsDNA.

DOl: https://doi.org/10.7554/eLife.39723.009

The following source data and figure supplements are available for figure 2 :

Figure supplement 1. McdA Activity.

DOl: https://doi.org/10.7554/eLife.39723.010

Figure supplement 1-source data 1. Source data for panel B.

DOl: https://doi.org/10.7554/eLife.39723.011

Figure supplement 1-source data 2. Source data for panel D.

DOl: https://doi.org/10.7554/eLife.39723.012

Figure supplement 1 -source data 3. Source data for panel F.

DOl: https://doi.org/10.7554/eLife.39723.013

Figure supplement 1-source data 4. Source data for panel G.

DOl: https://doi.org/10.7554/eLife.39723.014

prior data (Figures 1D and 2F, Figure 1-figure supplement 1A) that suggests C-terminal fusions of McdA may prevent interactions with McdB.

In comparison to classic examples within the ParA/ParB family, McdB's stimulation of McdA ATPase activity is relatively mild (2-3 fold; Figure 2G). We therefore assayed if this stimulatory effect 
was sufficient to influence McdA's binding to DNA substrates using a gel shift assay. As shown previously (Figure 1I), with ATP present, non-specific DNA fragments exhibit slowed mobility in the presence of increasing concentrations of purified His-MBP-McdA (Figure 21). Conversely, when the experiment was conducted with a constant concentration of His-MBP-McdA $(2.5 \mu \mathrm{M})$, the shift in DNA mobility was reversed by addition of increasing amounts of McdB-His (Figure 2J). This demonstrates that McdB favors the release of McdA from DNA. McdB-His alone did not exhibit any DNA binding activity in our gel shift assay (Figure 2K). Taken together, these results further support a direct interaction between $M c d A$ and $M c d B$, and suggest that $M c d B$ drives the removal of McdA from its DNA substrate; contributing to the emergent oscillatory dynamics of McdA we observe in vivo.

\section{McdB localizes to carboxysomes via interaction with major and minor shell components}

We next sought to elucidate McdB's localization in vivo. Similar to our native McdA reporters, we generated $\mathrm{N}$ - and $\mathrm{C}$-terminal $\mathrm{mNG}$ fusions of $\mathrm{McdB}$ in its native genomic locus downstream of mcdA. C-terminal fusions of McdB displayed a diffuse localization with random punctate-like patterns ( $\geq 99 \%$ of cells; $n=371$ cells) (Figure $3 \mathrm{~A}$ and Figure 3-figure supplement $1 \mathrm{~A}$ ). In contrast, $\mathrm{N}$-terminal mNG-McdB was observed as multiple discrete fluorescent foci near the central longitudinal axis of the cell ( $\geq 99 \%$ of cells; $n=699$ cells), a result that strongly resembles the localization pattern of native carboxysomes (Figure 3B and Figure 3-figure supplement 1B). We confirmed colocalization of $\mathrm{McdB}$ with carboxysomes by co-expression of the carboxysome fluorescent reporter in the mNG-McdB strain. Both the mNG-McdB and RbcS-mTQ signals strongly colocalized ( $\geq 99 \%$ of cells; Pearson's Correlation Coefficient $[P C C]=0.92 ; n=316$ cells) as fluorescent foci near the long central axis of the cell (Figure $3 C$ and Figure 3 -figure supplement $1 C$ ).

Next, we investigated if McdB's interaction with the carboxysome is direct, and if so, what carboxysome components bind McdB. During biogenesis, carboxysomes first form a core structure containing RuBisCO and carbonic anhydrase, which are coordinated into an ordered array through interactions with CcmM (Figure 3D) (Long et al., 2007; Cot et al., 2008; Long et al., 2010; Cameron et al., 2013). This core is thought to recruit outer shell proteins through the mediating protein $\mathrm{CcmN}$, thereby forming the carboxysome coat (Fan et al., 2012; Kinney et al., 2012) (Figure 3D). CcmK2 is the dominant shell protein that composes the facets of the shell, and which has been shown to directly interact with $\mathrm{CcmN}$ (Kinney et al., 2012). Along with $\mathrm{CcmK2}$, proteins $\mathrm{CcmO}, \mathrm{CcmL}, \mathrm{CcmK3}, \mathrm{CcmK} 4$, and $\mathrm{CcmP}$ are also recruited to complete compartmentalization (Figure 3E) (Tanaka et al., 2008; Tanaka et al., 2009; Rae et al., 2012; Cai et al., 2013), although the relative arrangement of these structural components of the shell remains uncertain. We explored if the outer shell proteins of the carboxysome could be involved in recruiting McdB through a bacterial two-hybrid screen. Using $\mathrm{N}$ - or $\mathrm{C}$-terminally tagged McdA or McdB as bait, the assay suggested only N-terminally tagged $\mathrm{McdB}$ interacts with the shell proteins $\mathrm{CcmK2}, \mathrm{CcmK3}, \mathrm{CcmK4}, \mathrm{CcmL}$, and $\mathrm{CcmO}$, but not $\mathrm{CcmP}$ (Figure $3 \mathrm{~F}$ and Figure 3-figure supplement 1D). In contrast, we did not find evidence for direct interaction between McdA and carboxysome shell proteins (Figure $3 \mathrm{~F}$ and Figure 3-figure supplement 1D).

\section{Carboxysome formation is required for the emergent oscillations of McdA}

To further investigate the association of McdB with the carboxysome, we examined mNG-McdB dynamics in a $S$. elongatus background that lacks functional carboxysomes. While carboxysomes are essential for growth under an ambient atmosphere, mutants deleted for the Carbon Concentrating Mechanism (ccm) operon ( $\triangle \mathrm{ccmK} 2 \mathrm{LMNO}$; Figure $3 \mathrm{G}$ ) can be recovered in high $\mathrm{CO}_{2}$ (Price et al., 1993; Cameron et al., 2013). We therefore examined the localization of mNG-McdB in a $\triangle c c m K 2 L M N O$ background and found that mNG-McdB signal was diffuse ( $\geq 99 \%$ of cells; $n=389$ cells) in the absence of carboxysomes (Figure 3H and Figure 3-figure supplement 1E), further indicating a recruitment of McdB to assembled carboxysomes. As expected, RbcS-mTQ signal was also diffuse in $\triangle \mathrm{ccmKK} 2 \mathrm{LMNO}$ cells, confirming the absence of carboxysomes (Figure $3 \mathrm{H}$ and Figure 3-figure supplement 1E). Interestingly, in the absence of carboxysomes, mNG-McdA did not oscillate and formed a homogenous distribution along the nucleoid similar to that of our mNG- 


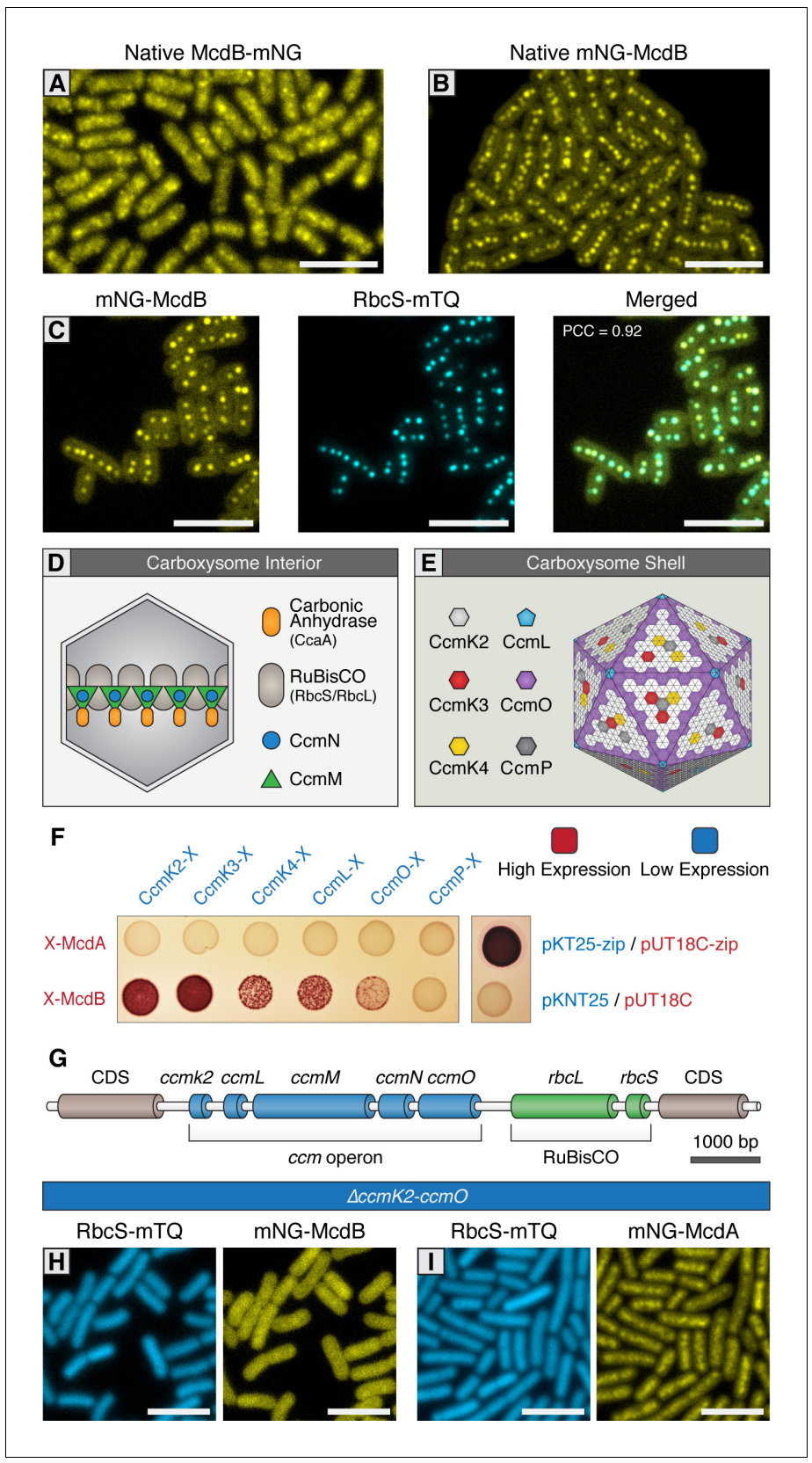

Figure 3. McdB interacts with the carboxysome shell. (A) Native McdB-mNG forms diffuse and punctate-like structures, while (B) native mNG-McdB localizes to centralized foci in S. elongatus cells. (C) mNG-McdB and a carboxysome reporter - RbcS-mTQ - colocalize. Pearson correlation coefficient (PCC) is 0.92. (D) Cartoon depiction of the internal and (E) external shell components of the cyanobacterial carboxysome, adapted from models presented in Rae et al., 2013. Note that the relative geometric arrangement of some shell components to one another remain somewhat speculative. (F) Bacterial two-hybrid of McdA and McdB against carboxysome shell proteins. Image representative of 3 independent trials. (G) Cartoon schematic of the $S$. elongatus carboxysome operon. $(\mathrm{H})$ In a $\Delta c c m K 2-O$ mutant without carboxysomes, mNG-McdB is not localized to central puncta but is diffuse, while (I) $\mathrm{mNG}-\mathrm{McdA}$ oscillatory dynamics are lost. All scale bars $=5 \mu \mathrm{m}$.

DOI: https://doi.org/10.7554/eLife.39723.015

The following figure supplement is available for figure 3:

Figure supplement 1. McdA/B bacterial two-hybrid against carboxysome shell proteins.

DOI: https://doi.org/10.7554/eLife.39723.016 
McdA $\Delta m c d B$ strain ( $\geq 99 \%$ of cells; $n=227$ cells) (Figure 3l, Figure 3-figure supplement $1 \mathrm{~F}$ and Figure 2D). This result suggests that the interaction and/or concentration of McdB onto carboxysomes is required for self-organization of $\mathrm{McdA}$ and could be an important prerequisite for strong stimulation of McdA ATPase activity.

\section{Carboxysome positioning is disrupted in McdA/McdB Mutants}

Since we found that both McdA and McdB are implicated in the regulation of carboxysome positioning, we next investigated how carboxysomes were distributed in strains lacking these proteins. To reduce potential off-target effects in the $\Delta m c d A$ and $\Delta m c d B$ lines, we generated knockouts in a manner designed to minimize alterations in expression of neighboring genes. This included insertion of the kanamycin resistance cassette outside of the McdA operon, and duplication of the $\mathrm{mcdA}$ promoter upstream of the $\mathrm{mcdB}$ gene in constructs where interruption of $\mathrm{mcd} A$ might be expected to disrupt downstream gene expression (see Figure 4AB). Simultaneously, we also inserted RbcS fused to mOrange2 $(\mathrm{mO})$ expressed from the native rbcS promoter to visualize carboxysomes (Figure 4ABC).

As before, $m$ NG-McdA distributed along the nucleoid and did not oscillate in $\triangle m c d B$ lines ( $\geq 99 \%$ of cells; $n=373$ cells) (Figure 4A), and carboxysomes were observed as large irregularly shaped polar fluorescent foci with smaller randomly distributed signals within the cell (Figure 4A). Consistent with our proposed role for $\mathrm{McdB}$ in removing McdA from the nucleoid, we did not observe depleted McdA signal on the nucleoid in the vicinity of carboxysomes within a $\triangle m c d B$ background. In $\triangle m c d A$ lines, mTQ-McdB still localized to carboxysomes, indicating McdA is not required for the association ( $\geq 99 \%$ of cells; PCC $=0.85 ; 416$ cells). Carboxysomes also formed large fluorescent foci in $\triangle m c d A$ lines and, where multiple foci could be resolved, they frequently clustered in close proximity rather than distributing throughout the cell (Figure $4 B$ ), similarly to $\triangle m c d B$ lines. In the absence of both $\operatorname{mcd} A$ and $\operatorname{mcdB}$, carboxysomes appeared as irregular foci of varying sizes randomly distributed through the cell ( $\geq 99 \%$ of cells; $n=399$ cells) (Figure $4 C$ ). The fluorescence intensity from the $\mathrm{RbcS}-\mathrm{mO}$ reporter was also unexpectedly $\sim 4$ fold weaker in these lines, likely due to unintended read-through effects from the mcdA promoter.

We next investigated carboxysome positioning in $\mathrm{McdA}$ and $\mathrm{McdB}$ overexpression lines. For these experiments, we inserted the RbcS-mO fluorescent reporter in neutral site 1, a genomically neutral locus (Clerico et alo, 2007), and overexpressed either mNG-McdA or mTQ-McdB from a synthetic riboswitch (Nakahira et al., 2013) inserted into neutral site 2 (Clerico et alo, 2007) (Figure 4DE). Upon the overexpression of mNG-McdA, we observed loss of McdA oscillation and the formation of large irregularly-shaped RbcS-mO fluorescent foci reminiscent of $\triangle m c d A, \triangle m c d B$ and $\triangle m c d A B$ lines ( $\geq 99 \%$ of cells; $n=340$ cells) (Figure $4 D$ ). With endogenous levels of McdB present, the McdA signal was generally depleted in the vicinity of these carboxysome aggregates. Upon overexpression of mTQ-McdB, we observed mTQ-McdB signal colocalized at irregularly-shaped RbcS-mO fluorescent foci as well as diffuse within the cell ( $\geq 99 \%$ of cells; PCC $=0.80 ; n=345$ cells) (Figure 4E). Moreover, we occasionally observed ( $<10 \%$ of cells) much larger RbcS-mO bar-shaped structures within the cell (Figure 4E; yellow arrow), indicating that McdB levels might influence carboxysome size and ultrastructure.

\section{Carboxysome ultrastructure is disrupted in McdA/McdB Mutants}

Carboxysome distribution displayed some variation even in wildtype strains, therefore we quantified carboxysome distributions in hundreds of cells utilizing MicrobeJ to automatically detect and characterize fluorescent carboxysome foci (Ducret et al., 2016). In our RbcS-mO only reporter line, carboxysomes were observed predominately along the central axis and mean focus diameter was $140 \mathrm{~nm}$ $\pm 100 \mathrm{~nm}$ (Figure 5A,G). In comparison to this strain, carboxysomes in $\triangle \operatorname{mcd} A(510 \mathrm{~nm} \pm 270 \mathrm{~nm})$, $\triangle m c d B(350 \mathrm{~nm} \pm 190 \mathrm{~nm})$, and $\triangle m c d A B(370 \mathrm{~nm} \pm 250 \mathrm{~nm})$ lines had a much broader distribution off the central axis with larger mean foci diameters and deviations (Figure 5BCDG). Likewise, overproduction of McdA produced carboxysome distributions off the central axis and a mean foci diameter $(320 \mathrm{~nm} \pm 300 \mathrm{~nm}$ ) similar to those of deletion lines (Figure 5BCDEG). Lastly, McdB overexpression produced carboxysomes that were distributed mostly along the central longitudinal axis, but exhibited the largest mean foci diameter and deviation (530 nm $\pm 470 \mathrm{~nm}$ ) (Figure 5FG). 


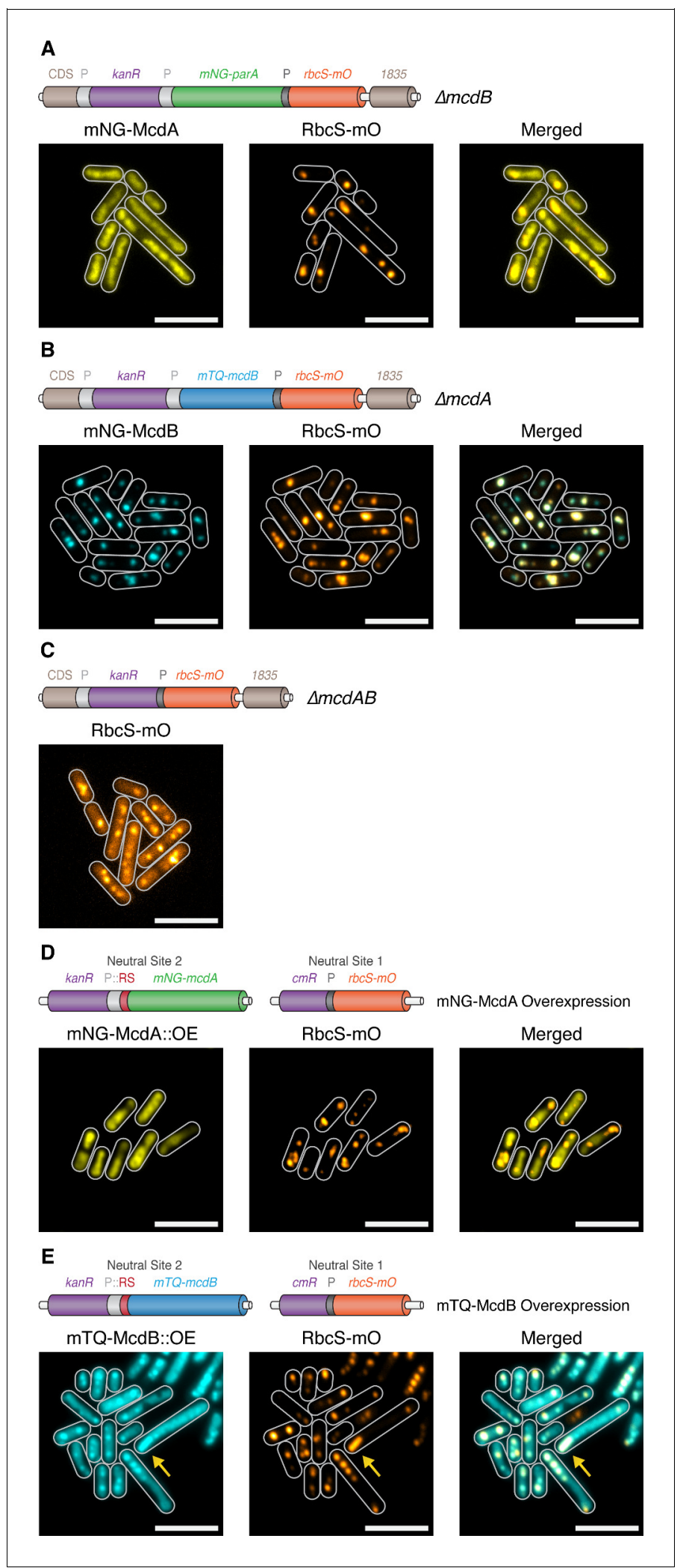

Figure 4. $\mathrm{McdA}$ and $\mathrm{McdB}$ are essential for distributing carboxysomes. (A) Carboxysome (orange; rbcS-mO) and mNG-McdA (yellow) distribution in a $\triangle m c d B$ background. Cartoon schematics (top) of the genetic construct are depicted, mcdA promoter ' $\mathrm{P}$ '=light grey, rbcS promoter = dark grey. $\mathrm{mNG}$-McdA signal did not oscillate and was found distributed on the nucleoid (B) Carboxysome and mTQ-McdB (cyan) distribution in a $\triangle$ mcdA background. Figure 4 continued on next page 
Figure 4 continued

mTQ-McdB colocalizes to $S$. elongatus carboxysomes (RbcS-mO) (PCC $=0.85)$. (C) Carboxysome distribution with mcdAB deleted. (D) Carboxysome positioning is disrupted and oscillation of mNG-McdA does not occur upon mNG-McdA overexpression. mNG-McdA signal did not oscillate and was found distributed on the nucleoid. Some carboxysomes had mNG-McdA signal depleted in their vicinity. Riboswitch (RS) = red. (E) Bar carboxysome structures (yellow arrow) and loss of carboxysome positioning are observed upon overexpression of mTQ-mcdB. $\mathrm{mTQ}-\mathrm{McdB}$ signal colocalized with RbcS-mO signal $(\mathrm{PCC}=0.80)$. All scale bars $=5 \mu \mathrm{m}$.

DOl: https://doi.org/10.7554/eLife.39723.017

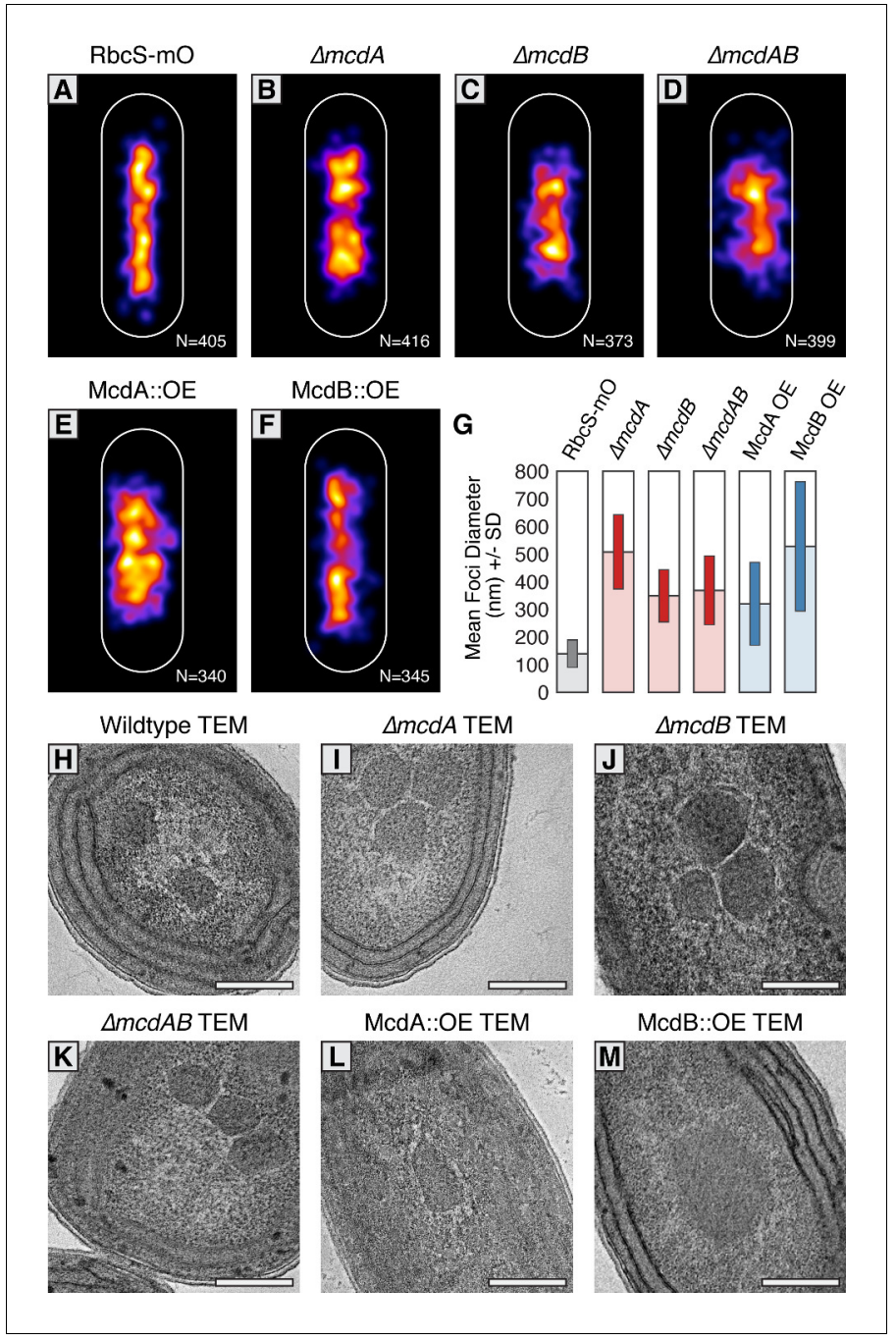

Figure 5. McdAB physically separate and regulate carboxysome ultrastructure. (A-F) MicrobeJ average distribution heat-map of carboxysomes in the indicated genetic background strains. Quantity of cells measured in lower right corner. (G) Mean RbcS-mO foci area and standard deviation for wildtype and the indicated mutant strains. (H-M) Electron micrographs of carboxysomes from wildtype and mutant strains. All scale bars $=250 \mathrm{~nm}$. DOl: https://doi.org/10.7554/eLife.39723.018

The following figure supplement is available for figure 5:

Figure supplement 1. Quantification of carboxysome size from TEM.

DOI: https://doi.org/10.7554/eLife.39723.019 
This data suggests that in addition to spatially regulating carboxysome distributions, McdA and McdB could influence carboxysome size and/or ultrastructure.

To differentiate whether the changes in size of RbcS-mO foci were due to clustering of multiple carboxysomes or changes in carboxysome ultrastructure, we used Transmission Electron Microscopy (TEM). In contrast to faithfully distributed carboxysomes in our wildtype TEM images (Figure $5 \mathrm{H}$ and Figure 5-figure supplement 1B), we observed multiple carboxysomes tightly clustered in our $\triangle m c d A, \triangle m c d B$, and $\triangle m c d A B$ strains (Figure 5IJK and Figure 5-figure supplement 1ACDE). This observation suggested $\mathrm{McdA}$ and $\mathrm{McdB}$ are required to separate neighboring carboxysomes, or that newly synthesized carboxysomes may be incompletely detached from one another during biogenesis (Cameron et al., 2013; Chen et alo, 2013) in the absence of McdA or McdB.

Upon overproduction of McdA, we observed irregularly-shaped carboxysomes with 'rounded' edges that tightly clustered (Figure $\mathbf{5 L}$ and Figure 5 -figure supplement 1AF). It should be noted however, that this cell line displayed severe growth arrest and possessed an unusually abundant number of granules which we suggest could be polyphosphate bodies based on their structure and dense staining. Consistent with this observation, overproduction of ParA family proteins in many organisms is lethal (Lasocki et al., 2007). Most strikingly, carboxysomes did not cluster in McdB overproduction strains either, instead, carboxysome ultrastructure was dramatically altered. Unlike the classic icosahedral-shape, carboxysomes were observed as large irregular bar-like structures (Figure 5M and Figure 5-figure supplement 1AG). In some instances, these 'bar-carboxysomes' extended hundreds of nanometers (Figure 4E), resembling previous reports of improperly assembled carboxysomes in cells lacking ccmL (Price and Badger, 1989; Cameron et al., 2013). Together, these results highlight the importance of the McdAB system for spatially separating carboxysomes and regulating the underlying size and ultrastructure.

\section{Carboxysomes locally deplete McdA on the nucleoid and are required for McdA oscillation}

In ParA-based plasmid partitioning, the low-copy number of plasmid cargo allows for the direct observation of how one or two plasmid copies influence the distribution of ParA on the nucleoid, and vice versa. Through in vivo and in vitro experimentation, it has been demonstrated that ParBbound plasmids and chromosomes form ParA depletion zones by stimulating the release of ParA from the nucleoid in their vicinity (Hatano et al., 2007; Ringgaard et al., 2009; Schofield et al., 2010; Hwang et al., 2013; Vecchiarelli et al., 2013; Vecchiarelli et al., 2014). But in S. elongatus, carboxysome copy-number correlates with cell length and ranges between 3 to 15 copies (Figure 1figure supplement $1 \mathrm{C}$ ). How multiple carboxysomes are equally spaced along the cell-length by a global oscillation of McdA protein is not intuitively obvious. Therefore, we wished to determine if McdB-bound carboxysomes also cause similar local depletions of McdA on the nucleoid and whether oscillation of McdA was a requirement for carboxysome motion and equidistant positioning, even at low-copy numbers.

In time-lapse experiments of mNG-McdA and RbcS-mTO strains, we frequently observed that carboxysomes move towards the highest local concentration of McdA on the nucleoid; this was especially apparent as the wavefront of the oscillating McdA pool approaches carboxysomes (Videos 35). The most rapid directed motions of carboxysomes were visible as the wavefront approaches a carboxysome, and then as the wavefront passes. To explore this observation in more depth, we developed the ability to regulate the initiation of carboxysome formation as well as to modulate the number of carboxysomes per cell. To accomplish this, we replaced the native ccmK2 promoter with a Ptrc promoter lacking the lacl repressor and attached a $5^{\prime}$ synthetic riboswitch preceding ccmK2 (RS::ccmK2LMNO; Figure 6A). In the absence of inducer, genes regulated by this riboswitch are tightly off, and expression is highly tunable with increasing concentrations of theophylline (Nakahira et alo, 2013). In the absence of theophylline, we observed that RbcS-

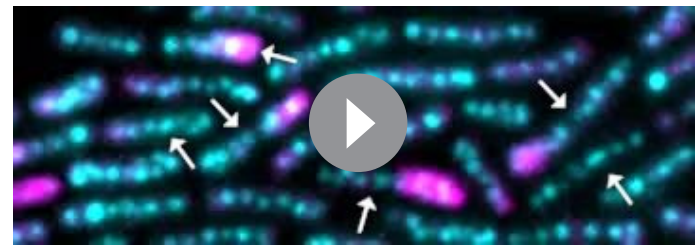

Video 4. Carboxysomes (blue; RbsS-mTQ) move towards increased concentrations of $\mathrm{mNG}-\mathrm{McdA}$ (magenta); notable examples of this phenomenon are denoted by white arrows. Each frame is 30 seconds. DOI: https://doi.org/10.7554/eLife.39723.021 


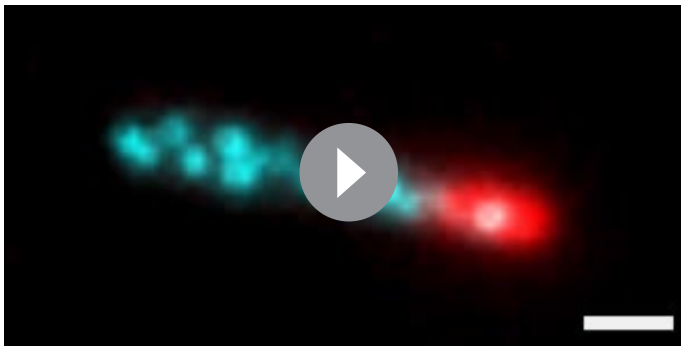

Video 5. Zoomed-in single cell representation of carboxysomes (blue; RbsS-mTQ) moving towards increased concentrations of mNG-McdA (red). Each frame is 15 seconds.

DOI: https://doi.org/10.7554/eLife.39723.022
mTQ signal was diffuse and mNG-McdA was distributed homogenously along the nucleoid ( $\geq 99 \%$ of cells; $n=204$ cells) (Figure 5-figure supplement $1 \mathrm{H})$, consistent with our prior results from $\triangle c c m K 2 L M N O$ mutants (Figure 31). When these strains were induced with either $400 \mu \mathrm{M}$ or $600 \mu \mathrm{M}$ theophylline, we were able to generate on average one or two carboxysomes per cell, respectively (Figure $6 \mathrm{BC}$ ). In the presence of 1 carboxysome, mNG-McdA signal remained evenly distributed except for a depletion zone that correlated with the nucleoid region in the vicinity of the carboxysome (Figure 6B). Likewise, with two carboxysomes, mNG-McdA signal again distributed along the nucleoid but was depleted in areas correlating to carboxysomes (Figure 6C). In either case, mNG-McdA signal was highly reduced in areas of RbcS-mTQ signal ( $\geq 99 \%$ of cells; PCC $=0.20 ; n=391$ cells), indicating McdBbound carboxysomes have $\mathrm{mNG}-\mathrm{McdA}$ depleted in their vicinity. In this strain, we performed realtime imaging of mNG-McdA dynamics and RbcS-mTQ motion. In instances where cells contained two, closely spaced carboxysomes, one carboxysome could be clearly observed to move in the direction of the higher McdA concentration (Figure 6D). When a sufficient distance was reached between the two carboxysomes, mNG-McdA was re-recruited to the depleted nucleoid region between the two carboxysomes (Figure 6D). As $\mathrm{mNG}-M c d A$ rebound the nucleoid, movement of the centralized carboxysome halted and slightly regressed back in the opposite direction (Figure 6D). This result is consistent with the Brownian-ratchet mechanism for genetic cargo movement towards the highest local concentration of ParA (Vecchiarelli et al., 2010; Vecchiarelli et al., 2014; Hu et al., 2017).

We next sought to determine if we could reconstitute carboxysome-dependent oscillation of McdA. Even at relatively high concentrations of theophylline inducer, our synthetic riboswitch was unable to generate wildtype quantities of carboxysomes. Therefore, we used a variant of a previously published approach (Cameron et al., 2013) by replacing the ccmK2 promoter with the Ptrc promoter and inserted an upstream lacl repressor (Figure 6E). This promoter is generally capable of driving higher expression levels of gene targets. In the absence of Isopropyl $\beta$-D-1-thiogalactopyranoside (IPTG), some carboxysome formation was observed due to leaky expression of the Ptrc promoter in cyanobacteria (Figure 6F). Similar to prior results, mNG-McdA was depleted in the vicinity of carboxysomes ( $\geq 99 \%$ of cells; $n=453$ cells) (Figure 6F). Following induction with IPTG, multiple carboxysomes formed throughout cells and $\mathrm{mNG}-\mathrm{McdA}$ oscillations emerged ( $\geq 99 \%$ of cells; $\mathrm{n}=439$ cells; Figure 6F). Altogether, these experiments strongly indicate that McdB is concentrated upon carboxysomes and that this localized pool of McdB changes the dynamics of McdA bound to neighboring regions of the nucleoid. Under conditions where there are relatively few (1-3) carboxysomes, McdB appears to continuously stimulate the release of nearby McdA. It is only at higher numbers of carboxysomes (4+) when a self-organized oscillation of McdA from end-to-end of the nucleoid emerges. Moreover, we observe multiple instances of directed motion of carboxysomes towards increased McdA concentrations on the nucleoid, consistent with the Brownian-ratchet model of cargo movement.

\section{Carboxysomes are hexagonally arranged when crowded on a nucleoid}

Carboxysomes are frequently described as being linearly arranged along the longitudinal axis of $S$. elongatus. In addition to linear distributions, we also routinely observed carboxysomes that were equidistant to each other, but no longer linearly arranged (Figure 7A). Instead, carboxysomes displayed a hexagonal packing phenomenon where the linear arrangement along the longitudinal axis looked kinked or displayed a zig-zag pattern. The hexagonal packing arrangement is non-intuitive assuming carboxysome distribution were to be based solely on either an underlying cytoskeleton or McdA oscillations, as these features are oriented longitudinally to the cell. Hexagonal packing was typically correlated with cells that had a high number of carboxysomes relative to the cell's length. 


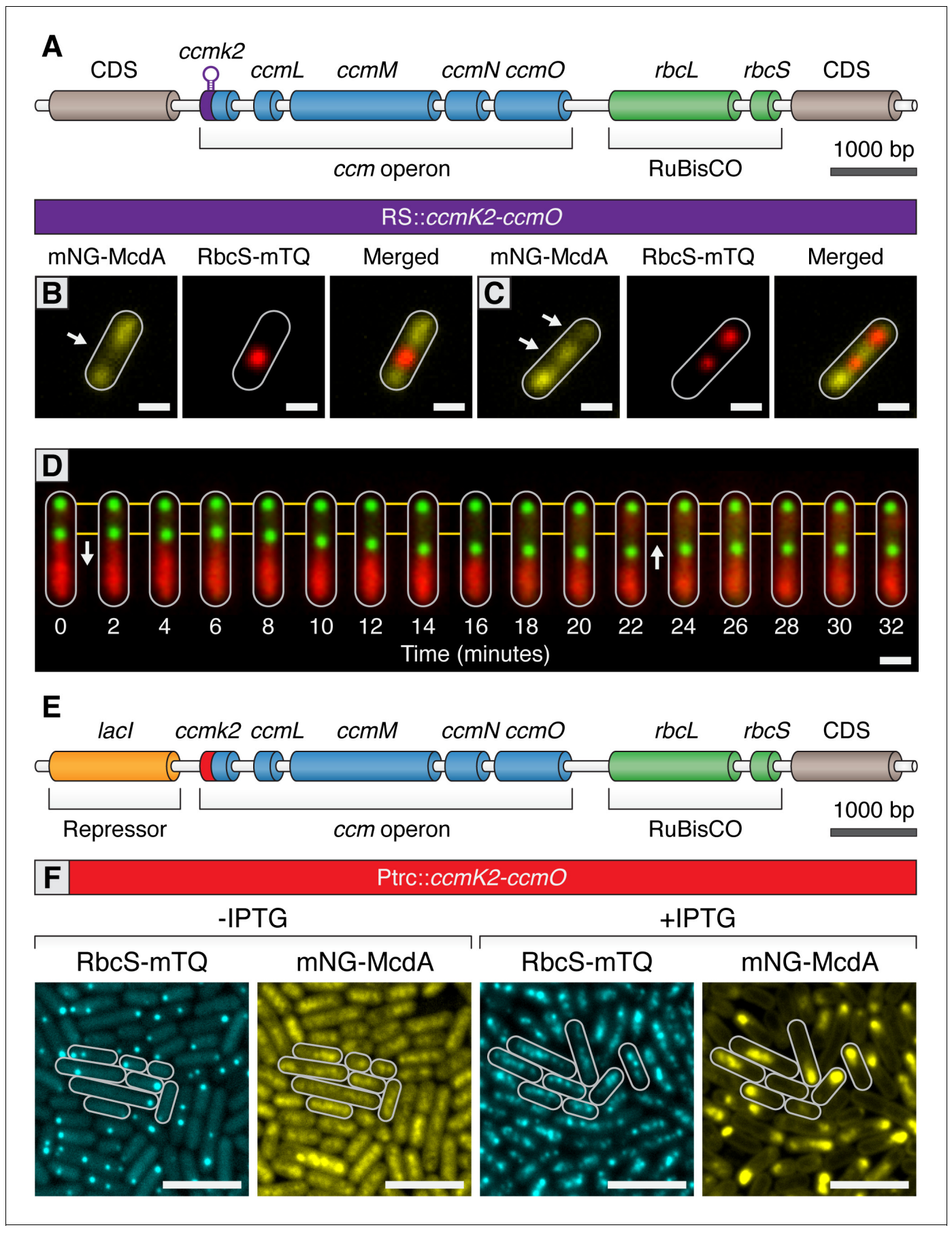

Figure 6. Carboxysomes locally deplete McdA from the nucleoid and cause McdA oscillation at high-copy number. (A) Cartoon schematic of the inducible carboxysome operon with the synthetic, theophylline-inducible riboswitch proceeding ccmK2. Induction of carboxysome biogenesis with either (B) $400 \mu \mathrm{M}$ or (C) $600 \mu \mathrm{M}$ theophylline leads to the formation of one or two carboxysomes (red; RbcS-mTurq). mNG-McdA (yellow) is depleted from the vicinity of nearby carboxysomes (white arrows). Scale bar $=1 \mu \mathrm{m}$. (D) In a representative timelapse imaging of a newly formed carboxysome (green), the central carboxysome moves towards (white arrow) a cellular location with increased mNG-McdA (red). When sufficient distance is obtained between carboxysomes ( $20 \mathrm{~min}$ ) mNG-McdA begins to be recruited between them. Scale bar $=1 \mu \mathrm{m}$. (E) Cartoon schematic of carboxysome operon with Ptrc promoter and lacl proceeding ccmK2. (F) mNG-McdA oscillations are reconstituted following addition of IPTG and the assembly of multiple carboxysomes. Scale bar $=5 \mu \mathrm{m}$.

DOI: https://doi.org/10.7554/eLife.39723.020 


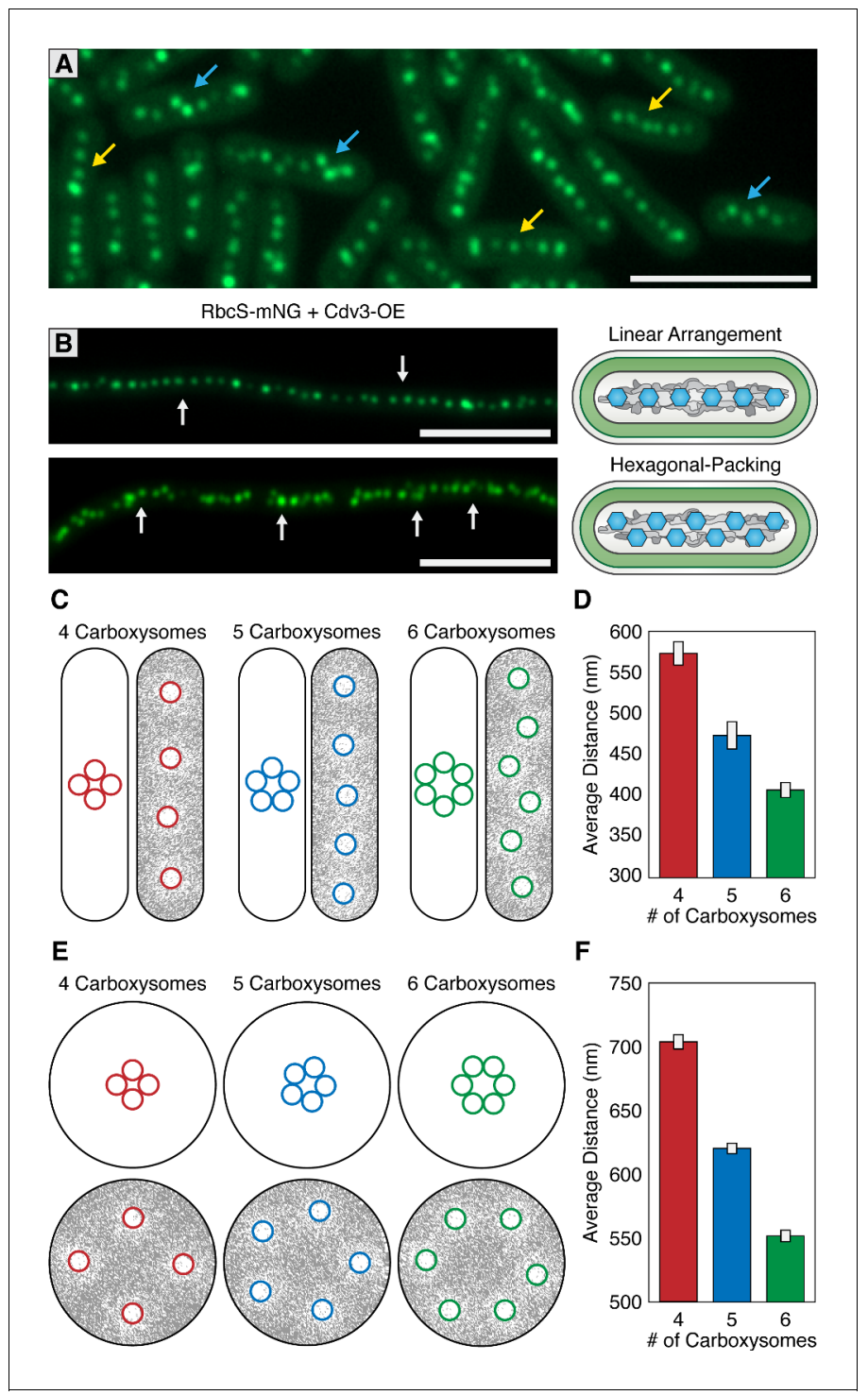

Figure 7. McdAB accounts for linear and hexagonal packing of carboxysomes. (A) In a field of $S$. elongatus cells, carboxysomes are found in either a linear (yellow arrow) or hexagonal (blue arrow) arrangement. Scale bar $=5 \mu \mathrm{m}$. (B) Linear or hexagonal arrangement of carboxysomes in filamentous cells (white arrows). Scale bar $=5 \mu \mathrm{m}$. (C) Reaction-diffusion simulations of 4,5, or six carboxysomes on a rounded-rectangle surface. Positions of carboxysomes in representative simulations indicated at the start of the simulation (left) and after the simulation has reached steady state (right). Grey $=$ McdA. White = Nucleoid. (D) Average distance between carboxysomes (E) Reaction-diffusion simulations of 4, 5, or six carboxysomes upon a round surface. Grey $=$ McdA. White $=$ Nucleoid. (F) Average distance between carboxysomes. Error bars = standard deviation. DOl: https://doi.org/10.7554/eLife.39723.023

The following figure supplement is available for figure 7:

Figure supplement 1. Carboxysomes fall between nucleoids in elongated cells lacking McdA or McdB. DOI: https://doi.org/10.7554/eLife.39723.024

However, it is difficult to ascertain if this different packing arrangement is due solely to carboxysome number, or any number of other factors that could be differentially regulated between distinct cells.

To better understand this hexagonal packing phenomenon, we examined carboxysome positioning in hyperelongated cells because these cells have unusual nucleoid features useful to supplement our observations in cells of wildtype length $(3-6 \mu \mathrm{m})$. Importantly, such hyperelongated $S$. elongatus cells are known to contain nucleoid clusters which are separated by intermittent cytoplasmic gaps 
that physically separate the nucleoid clusters from one another (Miyagishima et al., 2005); Figure 7-figure supplement 1). One targeted method to increase cell length is to overexpress the FtsZ regulatory protein $\mathrm{Cdv3}$, which we have previously reported to cause division arrest and subsequent cell elongation up to $2 \mathrm{~mm}$ (Jordan et al., 2017; MacCready et al., 2017). In cells elongated by this method, we observed both linear and hexagonal carboxysome packing (Figure 7B), sometimes observing different packing arrangements on neighboring nucleoid clusters within the same cell (Figure 7-figure supplement 1D). Carboxysomes in hyperelongated cells always co-localized with a nucleoid cluster, as visualized by DAPI staining (Figure 7-figure supplement 1A), and were never observed in the gaps between clusters, consistent with a role for McdAB in tethering carboxysomes to DNA. By contrast, in a $\Delta m c d A$ or $\Delta m c d B$ background, when we induced hyperelongation by expressing $\mathrm{Cdv3}$, carboxysomes were frequently observed in these cytoplasmic gap regions (Figure 7-figure supplement 1BC).

In individual hyperelongated cells, we frequently observed carboxysomes both in linear and hexagonal-packing arrangements within the same cell but on different nucleoid clusters (Figure 7-figure supplement 1D). Because cells containing both linear and hexagonal packing arrangements share the same cytosol, it is unlikely that the carboxysome packing is regulated by a global change within a cell (such as a diffusible factor). Instead, we found once again that the hexagonal packing was typically observed when the number of carboxysomes were higher on a given nucleoid cluster. These results suggest that carboxysome packing arrangement may be a self-emergent property related to the density of carboxysomes on a given nucleoid surface area.

\section{The Brownian-ratchet model is sufficient to explain carboxysome distributions}

To assess if the Brownian-ratchet model of carboxysome positioning could account for both carboxysome spacing and patterning (i.e. linear vs. hexagonal), we turned to an established in silico mathematical model that has successfully described several aspects of the Brownian-ratchet mechanism for ParA-mediated partitioning of plasmids (Hu et al., 2017). Since we have yet to determine which biochemical parameters of the Mcd system differ from that of traditional Par systems, in this treatment, we simply increased the number of cargo copies on the nucleoid matrix while keeping all other biochemical parameters as previously described so as to determine if increasing cargo copy number is enough to convert linear positioning into hexagonal packing. We programmed the geometry of the nucleoid surface area ( $2.5 \mu \mathrm{m}$ by $0.6 \mu \mathrm{m}$ rounded rectangle) and carboxysome cargo (175 $\mathrm{nm}$ ) based off of previously measured values of wildtype S. elongatus (Rae et al., 2012; Murata et al., 2016). All simulations are initiated with tightly clustered carboxysomes near the center of the nucleoid (Figure 7C; left images), but carboxysomes are allowed to travel towards the highest gradient of McdA using the previously-established parameter values.

With the Brownian-ratchet model, five or less carboxysomes will linearly distribute on a rectangular surface representative of S. elongatus' nucleoid (Figure 7C). As cargo number increases the linear arrangement is maintained, but with tighter spacing (Figure 7CD). However, above a certain density threshold (six or more cargos on the same nucleoid under our simulation parameters), cargo positioning switches from a linear arrangement to hexagonal packing, reminiscent of the in vivo distributions (Figure 7ABCD). This change in packing arrangement can be understood if each carboxysome is independently seeking the highest local concentration of McdA on the nucleoid: as carboxysome density increases, a staggered conformation maintains the maximal nearest-neighbor distance. As many other cyanobacterial species exhibit spherical morphology, including the model Synechocystis sp. PCC 6803, we also examined the predicted distribution of carboxysomes upon a $1.7 \mu \mathrm{m}$ circular nucleoid (Figure 7EF). We suggest that the linear arrangement of carboxysomes in rod-shaped cells is largely a byproduct of nucleoid geometry, and thus, cell morphology. In support of this proposition, many spherical (e.g., see Figure 1A in Kerfeld et al., 2005) and filamentous (e.g., see Figure 1 in Montgomery, 2015) cyanobacterial cells also show a hexagonal carboxysome arrangement. Furthermore, S. elongatus cells grown under environmental conditions that increase carboxysome synthesis also dominantly display hexagonal packing (e.g., see Figure 2 in Sun et al., 2016). 


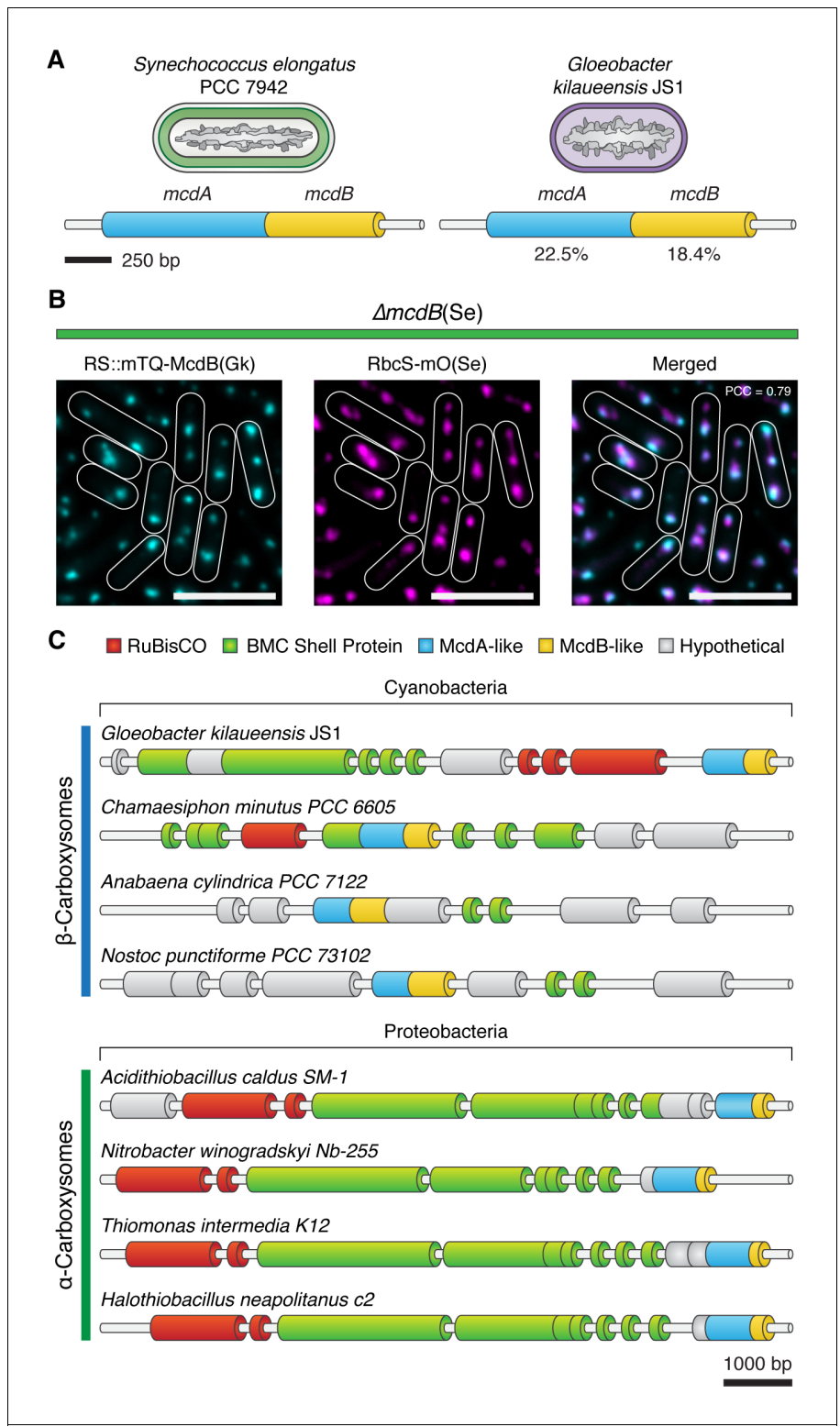

Figure 8. Evolutionary conservation of McdAB. (A) Cartoon illustration of McdAB operon structures in S. elongatus and Gloeobacter kilaueensis JS1. (B) Gloeobacter kilaueensis JS1 McdB colocalizes with S. elongatus carboxysomes (RbcS-mO). Scale bar $=5 \mu \mathrm{m}$. (C) McdA/B-like sequences colocalize in the genome with predicted carboxysome components across diverse microbes.

DOI: https://doi.org/10.7554/eLife.39723.025

\section{The McdAB system is evolutionarily wide-spread in cyanobacteria}

Homologs of ParA-type ATPases have been identified within extended carboxysome operons of cyanobacteria (Axen et al., 2014). Therefore, we examined other distant cyanobacterial species for possible McdAB homologs. One such case is the primitive thylakoid-less cyanobacterium Gloeobacter kilaueensis JS1, which drives expression of an $\mathrm{mcd} A$-like gene from the rbcL promoter. Interestingly, upon further examination, we found a small coding sequence following this $\mathrm{mcd} A$-like gene with weak similarity to $\mathrm{mcdB}$. BlastP determined that $S$. elongatus McdA had $22.5 \%$ pairwise sequence identity to the G. kilaueensis JS1 McdA-like protein, while S. elongatus McdB had only $18.4 \%$ pairwise identity to the McdB-like protein (Figure 8A). To investigate the possibility that the McdB-like protein of $G$. kilaueensis JS1 functions similarly to $S$. elongatus $M c d B$, we expressed a fluorescent fusion of the G. kilaueensis JS1 mcdB-like gene, mTQ-McdB(Gk), in our S. elongatus $\Delta m c d B$ strain. 
Despite the low primary sequence identity of $\mathrm{McdB}(\mathrm{Gk})$, we found that $\mathrm{mTQ}-\mathrm{McdB}(\mathrm{Gk})$ colocalized with RbcS-mO ( $P C C=0.79 ; n=248)$, indicating that $m T Q-M c d B(G k)$ can interact with $S$. elongatus carboxysomes (Figure 8B). These results suggest that carboxysome positioning by McdA and McdB may be widespread among cyanobacteria.

\section{Discussion}

\section{McdA is not cytoskeletal and utilizes the nucleoid to position carboxysomes}

Carboxysomes are essential components of the photosynthetic metabolism of cyanobacteria, yet the mechanisms underlying their positioning within the cell has remained an outstanding question. Prior work in S. elongatus showed that a ParA-like protein (McdA) was required for maintaining carboxysome positioning (Savage et alı, 2010). Largely influenced by models for DNA segregation by ParAtype ATPases at the time, the observation that C-terminally tagged McdA (McdA-GFP) oscillated in vivo and that carboxysomes were mispositioned following the disruption of McdA or MreB (an actinrelated component of the cytoskeleton) led to a widely-adopted hypothesis that carboxysomes were positioned by a cytoskeletal mechanism (Savage et al., 2010; Murat et al., 2010; Rae et al., 2013; Yokoo et al., 2015). This model proposed that adjacent carboxysomes were connected via McdA filaments that continually polymerize and depolymerize, exerting physical force upon carboxysomes in order to maintain their equidistant positioning - although no direct evidence for this model has been demonstrated to date.

Here we show that McdA-GFP homogeneously binds non-specifically to DNA, but exhibits no signs of filament formation (Figure $1 \mathrm{~A}-\mathrm{C}$ and Video 1). We show multiple lines of evidence indicating that McdA is capable of binding DNA in an ATP-dependent manner, and that the bulk of McdA in S. elongatus is concentrated upon the nucleoid. Furthermore, we identify a novel protein, McdB, that interacts with $\mathrm{McdA}$, stimulating its intrinsic ATPase activity and release from the nucleoid. Taken together, these results strongly suggest that McdA does not form independently-standing filaments, but instead attaches to the nucleoid body at the center of the cell, using it as a scaffolding surface to support an oscillating wave from one end of the cell to the other. We provide evidence that carboxysomes are in turn tethered to the nucleoid through interactions with $\mathrm{McdB}$, that in turn can bind McdA. Our results provide insight into the molecular mechanisms of McdA, and extend upon the limited characterization in the literature of this unusual ParA-family member. While we confirm that McdA can oscillate in vivo as was previously shown (Savage et al., 2010), we observe oscillatory waves that traverse the cell within $\sim 10 \mathrm{~min}$, which is significantly faster than that reported for McdA-GFP. The discrepancy may be related to the use of C-terminally tagged McdA reporters, which we find are unable to interact effectively with $\mathrm{McdB}$ and was originally over-expressed in a background with an additional endogenous copy of McdA (Savage et al., 2010). We observe activities for McdA (tagged on either terminus) that are consistent with other ParA family members, including ATP-dependent DNA binding (Figure 1A), self-association (Figure 2F and Figure 2-figure supplement 1A), and DNA stimulated ATPase activity (Figure 2H and Figure 2-figure supplement 1F). However, we also observe key distinctions between McdA and more canonical family members (see below), which may be important in the adaption of this system for the segregation of large protein cargos.

Importantly, we do not find any direct evidence supporting filament formation by McdA. Using high-resolution imaging techniques, we observe McdA-GFP to coat evenly across DNA in a carpeted flowcell, without any indication of large oligomer formation. While we cannot exclude the possibility that McdA-GFP fusions are disrupted in their capacity to form filaments, we note that this fusion retains many of its characteristics (Figure 1A, Figure 2-figure supplement 1A, and Figure 2-figure supplement 1F). Furthermore, our data suggests that the morphology of the cyanobacterial nucleoid is important for carboxysome positioning (Figures 1, 2JK, 3C, 6, 7), which could also explain why $\triangle m r e B$ mutants exhibit disorganized carboxysomes (Savage et alo, 2010). Both cell morphology and nucleoid topology are grossly altered in $\Delta m r e B$ strains (Hu et al., 2007), suggesting that the influence of MreB in carboxysome positioning is likely indirect. Instead, our results support an alternative model for McdA in carboxysome positioning that does not require an underlying cytoskeleton and which utilizes a Brownian-ratchet based mechanism (see below). 


\section{A unique system for distributing protein-based bacterial organelles}

Our model of self-organized carboxysome positioning is both informed by the ParA-based mechanisms used to segregate low-copy number plasmids, but also provides a novel platform to study the dynamics of self-organized protein segregation systems. Low-copy plasmids often contain DNA regions (e.g. parS) that bind ParB, which drives the directed and persistent movement of plasmids towards increased concentrations of ParA on the nucleoid (Vecchiarelli et al., 2010; Le Gall et al., 2016). In this way, it is proposed that ParA can provide a positional cue allowing plasmid cargo to 'surf' along the larger bacterial chromosome without a separate cytoskeletal system (Vecchiarelli et al., 2012).

While conceptual similarities exist between the better-established systems for plasmid positioning and results we report here for carboxysome positioning, a number of key distinctions separate $M c d A B$ from ParAB models. First, $S$. elongatus' McdA lacks the signature lysine residue in the Walker A box that defines the ParA family of ATPases (KGGXXGT; Figure 2G). The serine substitution in McdA at a position universally conserved in ParA members may underlie the unusually high ATPase activity of McdA (Figure 2G), which displays a maximum specific activity that is roughly twoorders of magnitude greater than that of other well-studied ParA systems (Vecchiarelli et al., 2010; Ah-Seng et alo, 2009). McdB is an even more divergent protein, bearing no identifiable sequence similarity to any known ParB proteins; indeed, no homologous proteins have been characterized in other species. This novel protein also recognizes and binds a large protein-based cargo (carboxysomes; Figure $3 C, F, H)$, further distinguishing it from all characterized ParB-like proteins that recognize genetic cargo. Even though McdB and ParB share no similarity, we find that McdB: (i) interacts with McdA (Figure 2F), (ii) stimulates McdA ATPase activity (Figure 2H) (iii) removes McdA from DNA (Figure 2J), and (iv) is responsible for emergent dynamics of McdA along the nucleoid (Figure 2D); analogous to the roles played by ParB in well-characterized plasmid partitioning systems. Furthermore, we observe that a pool of $\mathrm{McdB}$ enriched at the carboxysome is necessary to locally deplete McdA (Figures 4 and $6 B-D$ ), suggesting that prolonged McdB activity may stimulate the local release of McdA from the nucleoid. We propose that $\mathrm{McdB}$ is therefore acting to interface carboxysomes with nucleoid-bound McdA, processively pulling this protein cargo towards the highest local McdA concentration, and thereupon stimulating McdA ATPase activity and release (Figure 6D and Videos 3-5). The parallels between features of the McdAB system and Brownian ratchet ParAB models make it tempting to speculate that $M c d B$ has a distinct evolutionary origin from ParB-family members, but that these independent protein families convergently evolved to use nucleoid gradients of ParA-like proteins to segregate entirely different classes of macromolecular structures.

The colocalization of signal between mNG-McdB and carboxysomes (RbcS-mTQ) (Figure 3C), coupled with the carboxysome requirement for providing site-specificity to $\mathrm{mNG}-\mathrm{McdB}$ in vivo (Figure $3 H$ ), provide strong evidence that $\mathrm{McdB}$ is associating with carboxysomes and that this interaction is needed for emergent dynamics of McdA (Figure 31). It is curious that McdB is able to associate with a number of different shell proteins in our B2H assay (Figure 3F). Taken together with the evidence that a McdB homolog from G. kilaueensis JS1 with low sequence-identity still concentrated upon S. elongatus carboxysomes (Figure 8B), the most parsimonious hypothesis is that McdB-carboxysome shell interactions are mediated by structural and/or charge features common to many distinct shell proteins. Indeed, evolutionarily distant hexameric shell proteins of the bacterial microcompartment (BMC-H) family share a number of similarities in structural features and key residues at hexamer interfaces that are largely conserved (Cai et al., 2015; Sommer et al., 2017; Young et alo, 2017). This suggests some of these common structural features could be important in mediating interactions with $\mathrm{McdB}$, which might explain why McdB displays an interaction with different shell protein paralogs. Our B2H analysis also indicates that $\mathrm{McdB}$ may have a higher affinity to some shell proteins ( $\mathrm{CcmK} 2$ and $\mathrm{CcmK3}$ ) than others $(\mathrm{CcmK} 4, \mathrm{CcmL}$ and $\mathrm{CcmO}$ ) (Figure 3F). This may be related to the observation of clustered carboxysomes in $\Delta c c m K 3-4$ mutants (Rae et al., 2012), as this may reduce the amount of McdB recruited to the carboxysome surface. We note however, that given McdB's poor sequence conservation and without further knowledge of the structure and interaction domains of $M c d B$, we cannot rule out that McdB is a 'sticky' protein by the $\mathrm{B} 2 \mathrm{H}$ assay and is instead recruited through an alternative adaptor protein to the vicinity of carboxysomes. Moreover, deleting individual shell components, such as $\mathrm{CcmK2}, \mathrm{CcmL}$ or $\mathrm{CcmO}$, prevents mature 
carboxysomes formation and subsequent biogenesis (Cameron et al., 2013), preventing in vivo testing of $\mathrm{McdB} /$ carboxysomes interaction. Additional experiments will be required to identify the domain(s) that mediate McdB-shell interaction, and without a more detailed analysis, it remains possible that $\mathrm{McdB}$ can directly integrate within the shell of mature carboxysomes. Some indirect evidence would argue against the possibility that $\mathrm{McdB}$ is an integral shell protein, including both our observation that $\triangle m c d B$ strains did not possess a high CO2-requiring phenotype and McdB has not been identified in previously-published carboxysome purification studies (Faulkner et al., 2017).

\section{McdA oscillations are a consequence of multiple carboxysomes sharing the same nucleoid in a rod-shaped cell}

One surprising result of our study was that we observed that both McdB and carboxysomes themselves were required for the emergence of $\mathrm{McdA}$ oscillations along the nucleoid (Figure 2D, 3HI). Furthermore, a critical threshold number of carboxysomes were required to be localized on the same nucleoid in order for McdA oscillation to ensue (generally $>3$; Figure 6F). This suggests that it is not sufficient for McdB to be merely present, it must be specifically localized, concentrated, and/or activated to promote the McdA oscillations. Furthermore, we note that McdA oscillation per se is not required to segregate one carboxysome from another. In cells where we induced the formation of only two carboxysomes, or in cells were the $P_{\text {trc }}$ promoter was leaky, these carboxysomes reliably separated from one another despite the fact that no McdA oscillations were present (Figure 6DF). Likewise, our Brownian-Rachet simulations were able to recapitulate the separation between carboxysomes in silico without any requirement for an oscillating pool of McdA (Figure 7CDEF).

These results could suggest that 'global' McdA oscillations have a secondary role in regulating carboxysome positioning relative to the influence of local gradients of $\mathrm{McdA}$ on the nucleoid, and also raise other questions related to how McdA oscillations emerge. One possibility is that McdA oscillation itself might be a byproduct of the motion of multiple carboxysomes removing McdA along the nucleoid. Indeed, such a model has been proposed for plasmid segregation, termed 'DNA relay' (Surovtsev et al., 2016), where the plasmids recruit ParB to form cargo complexes that themselves oscillate from pole-to-pole in the cell, removing nucleoid-bound ParA in their wake. In the DNA relay model, the long-range motion of the cargo itself drives the emergent oscillation of ParA. Our simultaneous imaging of carboxysomes and McdA dynamics precludes such a model that would require long-range cargo movement (carboxysomes move much shorter distances and over longer time scales than the McdA oscillatory wave), but we cannot rule out more subtle carboxysome motions being involved in the emergence of McdA oscillations. The dynamics of carboxysome motion are complex at rapid time scales and are responsive to McdA wavefronts. During McdA oscillation, we observed that some carboxysomes at the wave front paused, and in some cases, were observed to get sucked into the approaching wave (Videos 3-5). While in the wave, carboxysome diffusion was suppressed. As the wave passed, carboxysome diffusion was anisotropic, drifting in the direction of the wave. Away from the wave, carboxysome diffusion was isotropic. An alternative hypothesis is that the global dynamics of McdA oscillation are dependent upon a balanced level of activities between $\mathrm{McdA}$ and $\mathrm{McdB}$. In this case, recruitment of soluble McdB to a defined location (the carboxysome) may concurrently act to remove it from the bulk cytosol, reducing the concentration that McdA perceives when not near a carboxysome. There is precedence for this interpretation in the ParA-like family of proteins, including the oscillatory behaviors of MinD and MinE. MinD binds to the plasma membrane when bound to ATP and exhibits an emergent pole-to-pole localization that is driven by the ATPase-stimulating activities of the partner protein MinE (Lutkenhaus, 2007). The ratio of these activities is important for their higher-order behaviors and when MinD:MinE ratios become severely unbalanced, oscillatory patterns collapse (Fange and Elf, 2006; Loose et alo, 2008; Loose et al., 2011; Zieske and Schwille, 2014; Vecchiarelli et al., 2016; MacCready et al., 2017).

It is intriguing to speculate whether McdA would oscillate in cyanobacteria displaying different morphologies, such as the spherical Synechocystis sp. 6803 or the filamentous Fremyella diplosiphon. While carboxysomes in these organisms are equidistantly spaced, they display a packing more reminiscent of the hexagonal arrangement rather than a linear distribution (e.g., see Figure 1A in Kerfeld et al., 2005; e.g., see Figure 1 in Montgomery, 2015). Our modeling suggests that this could be a natural outcome of the McdAB system operating on a nucleoid topology that is more 
spherical, rather than rod-shaped. While McdA oscillation could still be possible, it is unclear what patterns would be expected. Further analysis of McdAB dynamics in other cyanobacteria is required to elucidate the effects of nucleoid morphology on McdA pattern formation.

\section{McdA and McdB may facilitate biogenesis and regulate carboxysome size}

Our analysis provides a number of lines of evidence to suggest that McdA and McdB activities can also influence the ultrastructure of carboxysomes in $S$. elongatus. Cyanobacterial strains that are genetic knockouts of $\mathrm{mcdB}$ display carboxysomes that are significantly enlarged (Figure 5-figure supplement 1AD). Furthermore, overexpression of $\mathrm{McdB}$ resulted in massive carboxysome globules that sometimes spanned the entire short axis of the cell (Figure 5-figure supplement 1AG), while overexpression of McdA resulted in irregularly-shaped carboxysomes with rounded edges (Figure 5-figure supplement 1AF). While we cannot rule out the possibility of indirect effects, it is intriguing to speculate that $\mathrm{McdA}$ and $\mathrm{McdB}$ may act to directly regulate the size or shape of microcompartments as they are formed. In $S$. elongatus, it has been suggested that new carboxysomes bud off from existing carboxysomes (Cameron et al., 2013; Chen et al., 2013). Our model for carboxysome positioning requires that the interaction of $\mathrm{McdB}$ with $\mathrm{McdA}$ provide a pulling force exerted on the carboxysome shell that acts to processively move the protein compartment up an McdA gradient. It is therefore possible that these same molecular forces act during the synthesis of a new carboxysome. The relative ratio between $\mathrm{McdA}$ and $\mathrm{McdB}$ activities may play a role in the differences in carboxysome sizes observed under different environmental conditions or within different species. Future research will be required to confirm the role of McdAB systems in regulating the size of protein-based organelles.

\section{The McdAB system in other organisms}

Carboxysomes exist in two distinct forms, $\alpha$ and $\beta$, depending on the form of RuBisCO they encapsulate. While both are found in cyanobacteria, $\alpha$-carboxysomes also exist in many actinobacteria and proteobacteria. In these organisms, the vast majority of carboxysome-related genes tend to be found at genomic loci near the respective enzymes they encapsulate (Axen et alo, 2014). We find that $m c d A / B$-like sequences frequently fall in regions near $\alpha$ - and $\beta$-carboxysome operons (Figure $8 C$ ). We propose that the $m c d A / B$-like sequences near the $\alpha$-carboxysome operon could also function to equidistantly space $\alpha$-carboxysomes to ensure equal inheritance following cell division. Further study is now needed to determine how widespread the McdAB system is across evolutionary space. Indeed, many BMC classes exist, are widespread in bacteria, and encapsulate a wide array of enzymatic activities beyond Calvin-Benson-Bassham factors (Axen et alo, 2014; Kerfeld and Erbilgin, 2015). While putative McdB homologs are widespread in cyanobacteria and can be identified in many $\alpha$-carboxysome-containing proteobacteria (Figure $8 \mathrm{C}$ ), it is possible that a more comprehensive bioinformatic approach could identify similar factors associated with other classes of BMC. More broadly, these findings aid in understanding the spatial organization of other proteinbased mesoscale assemblies that encode ParA family members and are associated with diverse biological processes, including secretion (Perez-Cheeks et al., 2012; Viollier et al., 2002), conjugation (Atmakuri et alo, 2007), chemotaxis (Thompson et alo, 2006; Ringgaard et alo, 2011; Alvarado et al., 2017), and cell motility (Youderian et al., 2003; Kusumoto et al., 2008).

\section{Materials and methods}

\section{Construct designs}

All constructs in this study were generated using Gibson Assembly (Gibson et al., 2009) from synthetized dsDNA and verified by sequencing. Constructs contained flanking DNA that ranged from 500 to $1500 \mathrm{bp}$ in length upstream and downstream of the targeted insertion site to promote homologous recombination into target genomic loci (Clerico et al., 2007).

\section{Native fluorescent fusions}

For native McdA fluorescent fusions, the fluorescent protein mNeonGreen (mNG) was attached to either the $5^{\prime}$ or $3^{\prime}$ region of the native mcdA coding sequence, separated by a GSGSGS linker. Since 
Table 1. Cyanobacterial strains used in this study.

\begin{tabular}{|c|c|}
\hline Strain Name & Description/Genotype \\
\hline JSM-201 & $\mathrm{mNG}-\mathrm{Mcd} A$ \\
\hline JSM-202 & McdA-mNG \\
\hline JSM-203 & $\mathrm{mNG}-\mathrm{McdB}$ \\
\hline JSM-204 & McdB-mNG \\
\hline JSM-205 & $\mathrm{RbcS}-\mathrm{mO}$ \\
\hline JSM-206 & $m N G-M c d A+R b c S-m T Q$ \\
\hline JSM-207 & $m N G-M c d B+R b c S-m T Q$ \\
\hline JSM-208 & $\mathrm{mNG}-\mathrm{Mcd} A \Delta \mathrm{par} B$ \\
\hline JSM-209 & mNG-McdA $\Delta$ Synpcc7942_1834 \\
\hline JSM-210 & mNG-McdA $\Delta$ Synpcc7942_1835 \\
\hline JSM-211 & $m N G-M c d A+\Delta m c d B+R b c S-m O$ \\
\hline JSM-212 & $\Delta m c d A+m T Q M c d B+R b c S-m O$ \\
\hline JSM-213 & $\Delta m c d A+\Delta m c d B+R b c S-m O$ \\
\hline JSM-214 & $m N G-M c d A+\Delta m c d B+R b c S m O+R S:: m T Q-M c d B$ \\
\hline JSM-215 & $\Delta m c d A+m T Q M c d B+R b c S m O+R S:: m N G-M c d A$ \\
\hline JSM-216 & $m N G-M c d A+R b c S m T Q+\Delta c c m K 2-c c m O$ \\
\hline JSM-217 & $\mathrm{mNG}-\mathrm{McdB}+\mathrm{RbcS} \mathrm{mTO}+\Delta \mathrm{ccmK2}-\mathrm{ccmO}$ \\
\hline JSM-218 & mNG-McdA + RbcS mTQ+RS:: CcmK2 \\
\hline JSM-219 & $m N G-M c d A+R b c S$ mTQ+Ptrc::CcmK2 \\
\hline JSM-220 & $\mathrm{RbcS}-\mathrm{mTQ}+\mathrm{RS}:: \mathrm{Cdv3}$ \\
\hline JSM-221 & $m N G-M c d A+\Delta m c d B+R b c S m O+R S:: C d v 3$ \\
\hline JSM-222 & $\Delta m c d A+m T Q M c d B+R b c S m O+R S:: C d v 3$ \\
\hline JSM-223 & $m N G-M c d A+\Delta m c d B+R b c S m O+R S:: m T Q-M c d B(G k)$ \\
\hline
\end{tabular}

DOI: https://doi.org/10.7554/eLife.39723.026

the upstream coding sequence next to $m c d A$ is essential and presumably expressed from the same region of DNA as mcdA, the kanamycin resistance cassette was inserted upstream of the mcdA promoter to prevent operon disruption, and a duplicate $\operatorname{mcdA}$ promoter was inserted upstream of kanamycin to drive expression of the essential coding sequence. For the native McdB-mNG construct, mNG was inserted at the $3^{\prime}$ end of the mcdB coding sequence, separated by a GSGSGS linker, followed by the kanamycin resistance cassette. Alternatively, for the native mNG-McdB construct, the $m c d B$ sequence was codon optimized to prevent recombination at this site and $m$ NG was inserted at the $5^{\prime}$ end. The kanamycin resistance cassette was inserted downstream. To visualize carboxysomes, a second copy of the rbcS promoter and gene, attached at the $3^{\prime}$ end with either the fluorescent protein mTurquoise2 (mTO) or mOrange2 $(\mathrm{mO})$ and separated with a GSGSGS linker, were inserted into neutral site 1.

\section{Single Deletions}

Deletion constructs of plasmid parB, 1835, and $m c d B$ were created by replacing the respective coding sequences with a spectinomycin resistance cassette. Likewise, deletion of the carboxysome operon was performed by replacing the entire coding sequence, starting with the ccmK2 promoter and ending with $\mathrm{ccmO}$, with a spectinomycin resistance cassette.

\section{Native fluorescent fusions with deletion or overexpression}

For fluorescent and deletion lines, single plasmids were created that contained $5^{\prime}$ fluorescently labeled $m c d A$ ( $m N G$ ) or $m c d B(m T Q)$, separated by a GSGSGS linker, that simultaneously deleted $m c d A$ or $m c d B$ and integrated the rbcS::rbcS-mO fluorescent reporter upstream of the $\operatorname{mcdB}$ coding sequence (Figure $4 A B C$ ). In these lines, the kanamycin resistance cassette was inserted upstream 
similarly to our native mNG-McdA constructs (Figure $4 A B C$ ). For our $\triangle m c d A B$ strain, a codon optimized $\mathrm{rbcS}-\mathrm{mO}$ sequence was inserted to replace the entire $\mathrm{mcdA}$ operon while inserting the kanamycin resistance cassette upstream. Overexpression of $\mathrm{mNG}-M c d A$ or $\mathrm{mTQ}-\mathrm{McdB}$ were performed by insertion into neutral site two and expressed using a Ptrc promoter with an attached 5' theophylline riboswitch (Nakahira et al., 2013).

\section{Carboxysome induction systems}

To generate a tunable carboxysome operon, we replaced the native ccmK2 promoter with a Ptrc promoter in the absence of the lacl repressor and inserted a theophylline riboswitch (Nakahira et al., 2013) on the $5^{\prime}$ end of ccmK2. Alternatively, we also replaced the ccmK2 promoter with a Ptrc promoter without a $5^{\prime}$ riboswitch on ccmK2 and inserted the lacl repressor upstream. In both constructs, the spectinomycin resistance cassette was inserted upstream of the inserted promoters.

\section{Culture conditions and transformations}

All S. elongatus cultures were grown in $125 \mathrm{~mL}$ baffled flasks (Corning) containing $50 \mathrm{ml}$ BG-11 medium (SIGMA) buffered with $1 \mathrm{~g} \mathrm{~L}^{-1}$ HEPES to $\mathrm{pH}$ 8.3. Flasks were cultured in a Multitron II (atrbiotech.com) incubation system with settings: $80 \mu \mathrm{mol} \mathrm{m} \mathrm{m}^{-2} \mathrm{~s}^{-1}$ light intensity, $32^{\circ} \mathrm{C}, 2 \% \mathrm{CO}_{2}$, shaking at 130 RPM. Cloning of plasmids was performed in E. coli $\mathrm{DH} 5 \alpha$ chemically competent cells (Invitrogen). All S. elongatus transformations were performed as previously described (Clerico et al., 2007). Cells were plated on BG-11 agar with either $12.5 \mathrm{mg} \mathrm{ml}^{-1}$ kanamycin or $25 \mathrm{mg} \mathrm{ml}^{-1}$ spectinomycin. Single colonies were picked into 96-well plates containing $300 \mu \mathrm{l}$ of BG-11 with identical antibiotic concentrations. Cultures were verified for complete insertion via PCR and removed from antibiotics.

\section{Bacterial-two-hybrid analysis}

$\mathrm{N}$ - and C-terminal T18 and T25 fusions of McdA, McdB and shell proteins CcmK2, CcmK3, CcmK4, $\mathrm{CcmL}, \mathrm{CcmO}$ and $\mathrm{CcmP}$ were constructed using plasmid pKT25, pKNT25, pUT18C and pUT18, sequence-verified and co-transformed into E. coli BTH101 in all pairwise combinations (Karimova et al., 1998). Several colonies of T18/T25 cotransformants were isolated and grown in LB medium with $100 \mu \mathrm{g} / \mathrm{ml}$ ampicillin, $50 \mu \mathrm{g} / \mathrm{ml}$ kanamycin and $0.5 \mathrm{mM} \mathrm{IPTG}$ overnight at $30^{\circ} \mathrm{C}$ with 225 rpm shaking. Due to the self-assembling nature of carboxysome shell proteins, overnight IPTG induction for cotransformants bearing T18/T25 shell protein fusions was carried out at $0.1 \mathrm{mM}$ IPTG. Overnight cultures were spotted on indicator MacConkey plates supplemented with $100 \mu \mathrm{g} / \mathrm{ml}$ ampicillin, $50 \mu \mathrm{g} / \mathrm{ml}$ kanamycin and $0.5 \mathrm{mM}$ IPTG. Plates were incubated at $30^{\circ} \mathrm{C}$ up to $48 \mathrm{hr}$ before imaging.

\section{Induction strains}

Overproduction of $\mathrm{mNG}-\mathrm{McdA}$ and $\mathrm{mTQ}-\mathrm{McdB}$ were accomplished by inducing strains with 1500 $\mu \mathrm{M}$ theophylline for $48 \mathrm{hr}$. For carboxysome induction under the riboswitch, strains were incubated in $400 \mu \mathrm{M}$ theophylline (one carboxysome) or $600 \mu \mathrm{M}$ theophylline (two carboxysomes) for $24 \mathrm{hr}$ prior to imaging. Alternatively, for carboxysome induction under the Ptrc promoter and Lacl repressor, cells were incubated with $1000 \mu \mathrm{M}$ IPTG for $16 \mathrm{hr}$ prior to imaging. To increase cell lengths of the carboxysome reporter only strain or the $\Delta m c d A, \triangle m c d B$ and $\triangle m c d A B$ with the carboxysome reporter strains, RS::Cdv3 was overexpressed for 48 hours using $1500 \mu \mathrm{M}$ theophylline.

\section{Fluorescence microscopy}

All live-cell microscopy was performed using exponentially growing cells. Two $\mathrm{mL}$ of culture was spun down at 5000xg for $30 \mathrm{~s}$, resuspended in $200 \mu \mathrm{l}$ of BG-11 and $2 \mu \mathrm{l}$ transferred to a square $1.5 \%$ agarose +BG-11 pad on glass slides. All images were captured using a Zeiss Axio Observer A1 microscope (100x, 1.46NA) with an Axiocam 503 mono camera except the carboxysome induction experiments. Carboxysome induction experiments were performed using a Nikon Ti2-E motorized inverted microscope with LED-based light sources (100x, 1.45NA) with a Photometrics Prime 95B Back-illuminated sCMOS Camera. Image analysis was performed using Fiji v 1.0. 


\section{Transmission Electron Microscopy}

Cultures were grown to OD750 $=0.7$ in BG-11. Cells were pelleted and fixed overnight at $4{ }^{\circ} \mathrm{C}$ with $2.5 \%$ formaldehyde $/ 2.5 \%$ glutaraldehyde in $0.1 \mathrm{M}$ sodium cacodylate buffer $(\mathrm{pH} 7.4)$, suspended into a $2 \%$ agarose bead and cut into $\sim 1 \mathrm{~mm}$ cubes. Following three washes with $0.1 \mathrm{M}$ sodium cacodylate buffer, cells were suspended in $1 \%$ osmium tetroxide/1.5\% potassium ferrocyanide and incubated overnight at $4{ }^{\circ} \mathrm{C}$. After incubation, cells were washed with HPLC-quality $\mathrm{H}_{2} \mathrm{O}$ until clear. Cells were then suspended in 1\% uranyl acetate and microwaved for 2 min using a MS-9000 Laboratory Microwave Oven (Electron Microscopy Science), decanted, and washed until clear. Cells were dehydrated in increasing acetone series (microwave $2 \mathrm{~min}$ ) and then embedded in Spurr's resin (25\% increments for $10 \mathrm{~min}$ each at $25^{\circ} \mathrm{C}$ ). A final overnight incubation at room temperature in Spurr's resin was done, then cells were embedded in blocks which were polymerized by incubation at $60{ }^{\circ} \mathrm{C}$ for three days. Thin sections of approximately $50 \mathrm{~nm}$ were obtained using an MYX ultramicrotome (RMC Products), post-stained with $1 \%$ uranyl acetate and Reynolds lead citrate, and visualized on a JEM 100CX II transmission electron microscope (JEOL) equipped with an Orius SC200-830 CCD camera (Gatan).

\section{MicrobeJ quantification}

Cultures were grown to $\mathrm{OD}_{750}=0.7$ in $\mathrm{BG}-11$. Multiple individual images of the fluorescent reporters and chlorophyll autofluorescence were obtained for each strain and analyzed using MicrobeJ $5.11 \mathrm{n}$. In each line, cell perimeter detection was performed using the rod-shaped descriptor and default thresholding algorithm. Carboxysome detection was performed using the foci function with a tolerance of 15 and Z-score of 50. For fluorescent McdA lines, localization was quantified via detection of the single brightest point (tolerance $=2000$ ). For fluorescent McdB lines, localization was quantified via multiple smoothed foci detections (tolerance $=15$ and Z-score $=50$ ). Associations, shape descriptors, profiles and distances were recorded for each strain. Heatmaps were automatically generated with counts, contour and a spot size of 5. Mean foci area and standard deviation for each maxima was automatically calculated.

\section{McdA-GFP-6xHis expression and purification}

The gene sequence, mcdA-GFP-6xHis, was codon optimized for E. coli and synthesized by Genscript. The fragment was inserted into the $\mathrm{Ncol} / \mathrm{BamHI}$ cloning sites of the expression vector pET15b to create the pAV30 plasmid. pAV30 was transformed into BL21 (Al) cells (Invitrogen) and a $100 \mathrm{~mL}$ overnight culture containing $100 \mu \mathrm{g} / \mathrm{mL}$ of carbenicillin was grown at $20^{\circ} \mathrm{C}$ with shaking at $225 \mathrm{rpm}$. LB supplemented with $100 \mu \mathrm{g} / \mathrm{mL}$ of carbenicillin and a drop of Antifoam Emulsion (1 L per $2.5 \mathrm{~L}$ Fernbach flask $\times 4$ ) was pre-warmed to $37^{\circ} \mathrm{C}$ and inoculated with $10 \mathrm{~mL}$ of overnight culture per flask. The cells were grown at $37^{\circ} \mathrm{C}$ with shaking at $225 \mathrm{rpm}$ to an O.D. of 0.4 . The flasks were then plunged in an ice bath until the temperature of the culture dropped to $16^{\circ} \mathrm{C}$. Protein expression was then induced at O.D. 0.6 by the addition of $10 \mathrm{~mL}$ of a $0.1 \mathrm{M} \mathrm{IPTG} / 20 \%$ Arabinose solution to each flask. Cells were then grown overnight at $16^{\circ} \mathrm{C}$ with shaking at $225 \mathrm{rpm}(\sim 15 \mathrm{hr}$ induction). The cells were transferred to $1 \mathrm{~L}$ Beckmann bags and bottles, which were spun in a JLA 8.1 rotor at 4,500 rpm for $1 \mathrm{hr}$. The supernatant was poured out, and the cell pellets were frozen in the bags with liquid nitrogen and stored at $-80^{\circ} \mathrm{C}$. Frozen cell pellets were combined in a beaker with $10 \mathrm{~mL}$ of cold Lysis Buffer per gram of cell pellet $(-150 \mathrm{~mL}$ total), three Protease Inhibitor Mixture Tablets (Sigma) and $0.1 \mathrm{mg} / \mathrm{mL}$ lysozyme (Sigma). A homogenizer was used to ensure that the cell pellets were thoroughly dispersed, and two passes through a Microfluidizer lysed the cells. The lysate was cleared with a $30 \mathrm{~min}$ ultracentrifugation at $35,000 \mathrm{rpm}$ and $4^{\circ} \mathrm{C}$ using a $45 \mathrm{Ti}$ rotor. The lysate was then passed through a $0.45 \mu \mathrm{m}$ syringe filter. Using a peristaltic pump, the cleared lysate $(\sim 200 \mathrm{~mL})$ was loaded at a flow rate of $2 \mathrm{~mL} / \mathrm{min}$ onto a $5 \mathrm{~mL}$ HisTRAP HP cassette (GE) and equilibrated with Lysis Buffer (50 mM HEPES-KOH (pH 7.6), $1 \mathrm{M} \mathrm{KCl}, 10 \%$ Glycerol, 20 mM Imidazole (pH 7.4), 2 mM $\beta$-mercaptoethanol). The protein was eluted with a $20 \mathrm{mM}$ to $1 \mathrm{M}$ imidazole gradient (total volume $=60 \mathrm{~mL}$ ). Peak protein fractions were pooled and concentrated using an Amicon Ultra Centrifugal Device (10 KD MWCO). The sample was passed through a 26/10 salt-exchange column equilibrated in Q-Buffer (50 mM HEPES-KOH (pH 7.5), 200 mM KCl, 10\% Glycerol, 0.1 mM EDTA, 2 mM DTT). The sample was then immediately loaded onto a $1 \mathrm{~mL}$ Mono Q 5/50 anion exchange column (GE) equilibrated in Q-Buffer. The protein was eluted with a $200 \mathrm{mM}$ to $1 \mathrm{M} \mathrm{KCl}$ gradient. Peak 
fractions were pooled and concentrated to a no more than $100 \mu \mathrm{M}$. The sample was then separated over a 10/300 GL Superdex200 gel-filtration column equilibrated in Q Buffer (but with $600 \mathrm{mM} \mathrm{KCl}$ ). Peak fractions were pooled, concentrated to no more than $100 \mu \mathrm{M}$, frozen with liquid nitrogen, and stored at $-80^{\circ} \mathrm{C}$.

\section{6xHis-MBP-McdA expression and purification}

Due to insolubility issues encountered when expressing McdA-6xHis, a construct was designed where a 6xHis-MBP-tag was encoded upstream of a Tobacco Etch Virus (TEV) cleavage site and fused to the $\mathrm{N}$-terminus of the mcdA gene in a pET15b expression backbone to create pAH2 plasmid. pAH2 was transformed into ArcticExpress (DE3) competent cells (Agilent) and protein expression was carried out by growing transformants at $37^{\circ} \mathrm{C}$ and $225 \mathrm{rpm}$ until an OD600 of 0.6-0.8 was reached. Following an ice bath plunge to lower the culture temperature to $15^{\circ} \mathrm{C}$, protein expression was induced with the addition of $0.5 \mathrm{mM}$ IPTG. Induction was allowed to continue overnight at $15^{\circ} \mathrm{C}$. The cells were pelleted, flash frozen with liquid nitrogen, and stored at $-80^{\circ} \mathrm{C}$. Cells were then lysed

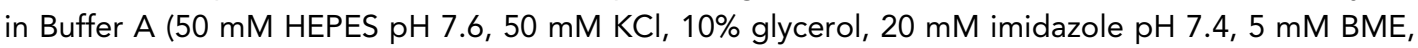
$50 \mu \mathrm{g} / \mathrm{ml}$ lysozyme, $1.25 \mathrm{kU}$ benzonase, 2 Protease Inhibitor Cocktail tablets) using a probe sonicator with $15 \mathrm{~s}$ on, $15 \mathrm{~s}$ off pulsation for $8 \mathrm{~min}$. Cell debris was removed by centrifugation at 14,000 rpm for $40 \mathrm{~min}$ in a FiberliteTM F15-8 $\times 50$ cy Fixed Angle Rotor (ThermoFisher Scientific) and the resulting lysate was filtered through a $0.45 \mu \mathrm{m}$ syringe filter prior to being loaded onto a HiTrapTM Q HP $5 \mathrm{ml}$ cassette (GE) connected in tandem to a $5 \mathrm{ml}$ HiTrapTM TALON Crude cassette (GE). The protein was eluted from the $\mathrm{Q}$ cassette with a $50 \mathrm{mM}-1 \mathrm{M} \mathrm{KCl}$ gradient in an anion exchange chromatography step. The His-tagged protein was then eluted from the TALON column with a $20 \mathrm{mM}-$ $1 \mathrm{M}$ imidazole gradient. Peak fractions were pooled, concentrated and further separated by gel filtration on a Superdex200 10/300 GL column (GE) pre-equilibrated with $50 \mathrm{mM}$ HEPES pH 7.6, 50 mM $\mathrm{KCl}, 10 \%$ glycerol, $5 \mathrm{mM}$ DTT. Individual peak fractions were concentrated to no higher than $20 \mu \mathrm{M}$ and frozen aliquots were kept at $-80^{\circ} \mathrm{C}$.

\section{McdB-6xHis expression and purification}

A codon-optimized gene sequence of $\mathrm{mcdB}-6 \mathrm{xH}$ is was inserted into the $\mathrm{Ncol} / \mathrm{BamHI}$ cloning sites of the expression vector $\mathrm{pET} 15 \mathrm{~b}$, yielding pAV42 plasmid. The construct was transformed into BL21(AI) and protein expression was carried out in the same manner as McdA-GFP-His. Frozen cell pellets were thawed and resuspended in lysis buffer containing $50 \mathrm{mM} \mathrm{HEPES} \mathrm{pH} \mathrm{7.6,500} \mathrm{mM} \mathrm{KCl,} 10 \%$ glycerol, $20 \mathrm{mM}$ imidazole $\mathrm{pH}$ 7.4, $5 \mathrm{mM} \mathrm{MgCl}$, $2 \mathrm{mM} \mathrm{BME,} 50 \mu \mathrm{g} / \mathrm{ml}$ lysozyme, $1.25 \mathrm{kU}$ benzonase, 2 Protease Inhibitor Cocktail tablets. Resulting cell lysate was centrifuged, filtered and loaded onto a $5 \mathrm{ml}$ His-Trap ${ }^{\mathrm{TM}} \mathrm{Ni}-\mathrm{NTA}$ cassette (GE). Following protein elution with a $20 \mathrm{mM}-1 \mathrm{M}$ imidazole gradient, peak fractions were pooled, concentrated and loaded onto a Superdex200 HiLoad 16/600 PG column pre-equilibrated with $50 \mathrm{mM}$ HEPES $\mathrm{pH} 7.6,500 \mathrm{mM} \mathrm{KCl}, 10 \%$ glycerol, $5 \mathrm{mM} \mathrm{MgCl}_{2}, 2 \mathrm{mM}$ DTT for final separation. Peak fractions were concentrated to no more than $70 \mu \mathrm{M}$ and flash frozen aliquots were kept at $-80^{\circ} \mathrm{C}$.

\section{ATPase assay}

ATPase assays were performed in a buffer containing $50 \mathrm{mM}$ HEPES (pH 7.6), $10 \mathrm{mM} \mathrm{MgCl}, 100$ $\mathrm{mM} \mathrm{KCl}, 0.1 \mathrm{mg} / \mathrm{ml} \mathrm{BSA}, 2 \mathrm{mM}$ DTT, and $0.1 \mathrm{mg} / \mathrm{ml}$ sonicated salmon sperm DNA (when present). Unlabeled ATP was spiked with $\left[\gamma^{32} \mathrm{P}\right]$-ATP and purified from contaminating ${ }^{32} \mathrm{P}_{\mathrm{i}}$ prior to use with a $1 \mathrm{ml}$ gel filtration (P-2 fine resin, Bio-Rad) column. The radiolabeled ATP mix was added to reactions at $1 \mathrm{mM}$. Reactions were assembled on ice at the protein concentrations indicated, with His-MBPMcdA, McdA-GFP-His, F SopA-His or P1 ParA being added last. The $20 \mu$ l reactions were incubated for $1 \mathrm{hr}$ at $30^{\circ} \mathrm{C}$ and immediately quenched by adding $10 \mu \mathrm{l}$ of a $1 \%$ SDS, $20 \mathrm{mM}$ EDTA solution. Two microliters of the quenched reactions were spotted and analyzed by thin-layer chromatography as previously described (Fung et al., 2001). Due to the feeble ATPase activities of SopA-His and P1 ParA, specific activities were determined from experiments carried out as shown above, but the $30^{\circ} \mathrm{C}$ incubation period was carried out for $3 \mathrm{hr}$. 


\section{DNA binding assay}

Electrophoretic mobility shift assays (EMSAs) were performed in a final reaction volume of $10 \mu \mathrm{l}$ in a buffer containing $50 \mathrm{mM}$ HEPES ( $\mathrm{pH}$ 7.6), $5 \mathrm{mM} \mathrm{MgCl}_{2}$, and $100 \mathrm{mM} \mathrm{KCl}$ with $10 \mathrm{nM}$ pUC19 plamsid $(2.8 \mathrm{~kb})$ as the DNA substrate. At the concentrations indicated, McdA-GFP-His or His-MBP-McdA was incubated for $30 \mathrm{~min}$ at $23^{\circ} \mathrm{C}$ with ADP, ATP or ATP $\gamma \mathrm{S}(1 \mathrm{mM})$. When used, McdB-His was added at the concentrations specified. Reactions were then mixed with $1 \mu \mathrm{l} 80 \%$ glycerol, run on $1 \%$ agarose gel in $1 \mathrm{X} T A E$ at $110 \mathrm{~V}$ for $45 \mathrm{~min}$ and stained with ethidium bromide for imaging. The peak fractions representing the dimer form of His-MBP-McdA from Superdex200 size exclusion chromatography were used.

\section{TIRFM of McdA-GFP binding to a DNA-carpeted flowcell}

Quartz flowcell construction and DNA-carpeting of the flowcell surface were performed as previously described (Vecchiarelli et al., 2014). For the imaging of McdA-GFP-His binding to the DNA carpet, prism-type TIRFM was performed using an Eclipse TE2000E microscope (Nikon) with a PlanApo $60 \times \mathrm{NA}=1.40$ oil-immersed objective and magnifier setting at $1.5 \times$. Movies were acquired using an Andor DU-897E camera (Andor Technology) with integrated shutter. The camera settings were digitizer, $3 \mathrm{MHz}$ (14-bit gray scale); preamplifier gain, 5.2; vertical shift speed, $2 \mathrm{MHz}$; vertical clock range: normal, electron-multiplying gain $40, E M C C D$ temperature set at $-98^{\circ} \mathrm{C}$, baseline clamp $\mathrm{ON}$, exposure time $100 \mathrm{~ms}$, frame rate $0.5 \mathrm{~Hz}$. The baseline of $\sim 100$ camera units was subtracted from the intensity data. The excitation for McdA-GFP-His was provided by $488 \mathrm{~nm}$ diode-pumped solidstate (Sapphire, Coherent) laser. Total internal reflection fluorescence illumination had a Gaussian shape in the field of view with measured horizontal and vertical half maximum widths of $\sim 65$ $\mu \mathrm{m} \times 172 \mu \mathrm{m}$ at $488 \mathrm{~nm}$. Intensity data for the DNA carpet-bound populations of McdA-GFP were taken from the middle of the illumination profile. The laser power of $488 \mathrm{~nm}$ illumination was $15 \mu \mathrm{W}$. Metamorph seven software (Molecular Devices) was used for camera control and image acquisition. ImageJ was used for analysis. The display brightness and contrast were set to the same levels for all TIRFM movies. ImageJ was used for conversion of Metamorph movies (.stk) into. avi format and Adobe Premiere was used for added text. Movie accelerations are indicated in the movie and figure legends.

McdA-GFP $(0.5 \mu \mathrm{M})$ was preincubated in McdA Buffer [50 mM Hepes (pH 7.6), $100 \mathrm{mM} \mathrm{KCl}, 10 \%$ (vol/vol) glycerol, $5 \mathrm{mM} \mathrm{MgCl} 2,2 \mathrm{mM} \mathrm{DTT}, 0.1 \mathrm{mg} / \mathrm{mL} \alpha$-casein, $0.6 \mathrm{mg} / \mathrm{mL}$ ascorbic acid] with 1 $\mathrm{mM}$ of the indicated nucleotide (or no nucleotide). The sample was incubated for $15 \mathrm{~min}$ in a $1 \mathrm{ml}$ syringe connected to one of the two inlets of a Y-shaped flowcell. The sample was infused onto the DNA carpet at a rate of $20 \mu \mathrm{L} / \mathrm{min}$. The fluorescence intensity of McdA-GFP that bound the DNA carpet was measured over time. At $t=3 \mathrm{~min}$, flow from the sample inlet was stopped and immediately switched to the second inlet that was connected to a wash buffer (McdA Buffer without McdAGFP or nucleotide). Wash buffer was flowed at a rate of $20 \mu \mathrm{L} / \mathrm{min}$, and the decrease in fluorescence intensity was monitored over time. The two-inlet flowcell had a Y-patterned configuration and imaging took place at the point of flow convergence to minimize the effect of protein rebinding to the DNA carpet during dissociation when flow was switched to the wash buffer.

\section{Theoretical model and computational method}

We find that McdA, McdB, and the carboxysome cargo show in vivo dynamics strikingly similar to that found for ParA-mediated DNA partition systems. Therefore, we leveraged our established Brownian ratchet model of ParA/ParB-mediated partition (Hu et al., 2015; Hu et al., 2017) to theoretically interrogate the carboxysome positioning process in cyanobacteria.

Briefly, the model describes the mechanochemical interplay between nucleoid-bound McdA and carboxysome-bound McdB. McdA and McdB in the current model fulfil exactly the same roles of ParA and ParB as in the low-copy plasmid partition case, respectively. While carboxysome alone diffuses randomly, its motility can be greatly modulated when carboxysome-bound McdB interacts with nucleoid-bound McdA. Specifically, carboxysome-bound McdB stimulates the ATPase activity of nucleoid-bound McdA, which triggers the dissociation of McdA from the nucleoid substrate surface. The slow rate of dissociated McdA resetting its DNA-binding capability generates an McdAdepleted zone behind the moving cargo. The resulting asymmetric McdA distribution perpetuates the directed movement of the carboxysome cargo. Transient tethering arising from the McdA-McdB 
contacts collectively drives forward movement of the cargo and also quenches diffusive motion in orthogonal directions. This way, McdA/McdB interaction - when at proper mechanochemical coupling - drives directed and persistent movement of carboxysomes ( $\mathrm{Hu}$ et al., 2015; Hu et al., 2017).

The model treats carboxysomes as circular disks that move on the nucleoid surface, which is modeled as a 2D simulation domain. The simulation domain is bounded by the reflective boundary condition. To study the effects of nucleoid geometry on carboxysome positioning, we constructed the simulation domains to mimic I.) a circular nucleoid and II.) a more elongated rounded rectangle nucleoid, which consists of a rectangle with two spherical caps at the ends of its long axis.

We simulated the model by the same kinetic Monte Carlo technique as in (Hu et al., 2015; Hu et al., 2017), which describes the coupling between the stochastic reaction-diffusion processes involving $M c d A$ and $M c d B$, and their mechanochemical interplay. Specifically, we investigated the effects of carboxysome number and nucleoid geometry on carboxysome positioning. In each case defined by different carboxysome number and nucleoid geometry, the simulation starts with the initial positions of the carboxysomes that cluster around the center of the simulation domain (see Figure 7CE in the main text). For each case, we identify the parameter regime in which the carboxysomes undergo 'directed segregation' - a motility mode in which the cargoes move away from each other and then become relatively stationary (e.g., see Figure 3 in Hu et al., 2017). That is, the carboxysomes are segregated and then stably positioned with a large inter-spacing. We then tracked the time evolutions of each of the simulated trajectories that are 10 min long, from which the final positions of, and separation distances between, carboxysomes were then calculated and reported in each case (average \pm standard deviation, $n=36$ trajectories).

\section{Acknowledgements}

We would like to thank the labs of Dr. Matthew Chapman and Dr. Kiyoshi Mizuuchi labs for use of equipment and reagents, as well as Dr. Cheryl Kerfeld and Dr. Beronda Montgomery for helpful conversations and suggestions in preparing this manuscript. The pET15b expression vector used for HisMBP fusion to McdA was a kind gift from Dr. Maria Schumacher. Purified P1 ParA and F SopA-His were kind gifts from the Funnell and Mizuuchi labs respectively. This work was supported by the National Science Foundation (Award Numbers 1517241; to KWO and DCD and 1817478; to AGV) and by research initiation funds to AGV provided by the MCDB Department, University of Michigan. Additional institutional and equipment support was provided by Office of Basic Energy Sciences, Office of Science, US Department of Energy (DE-FG02-91ER20021; to DCD).

\section{Additional information}

Funding

Funder

Grant reference number Author

\begin{tabular}{lll}
\hline National Science Foundation & 1517241 & $\begin{array}{l}\text { Katherine W Osteryoung } \\
\text { Daniel C Ducat }\end{array}$ \\
\hline National Science Foundation & 1817478 & Anthony G Vecchiarelli \\
\hline Basic Energy Sciences & DE-FG02-91ER20021 & Daniel C Ducat \\
\hline
\end{tabular}

The funders had no role in study design, data collection and interpretation, or the decision to submit the work for publication.

Author contributions

Joshua S MacCready, Conceptualization, Data curation, Formal analysis, Validation, Investigation, Visualization, Methodology, Writing-original draft, Conceived the project, Designed experiments, Performed all experiments; Pusparanee Hakim, Data curation, Formal analysis, Validation, Investigation, Methodology, Designed experiments, Performed all experiments; Eric J Young, Data curation, Formal analysis, Validation, Visualization, Performed all experiments; Longhua Hu, Data curation, Software, Formal analysis, Validation, Methodology, Performed all experiments, Designed and 
carried out computer simulations; Jian Liu, Data curation, Software, Formal analysis, Supervision, Validation, Methodology, Designed and carried out computer simulations; Katherine W Osteryoung, Funding acquisition, Writing-original draft; Anthony G Vecchiarelli, Conceptualization, Resources, Data curation, Formal analysis, Supervision, Funding acquisition, Validation, Investigation, Methodology, Writing-original draft, Conceived the project, Designed experiments, Performed all experiments; Daniel C Ducat, Conceptualization, Supervision, Funding acquisition, Methodology, Writing-original draft, Conceived the project, Designed experiments

Author ORCIDs

Joshua S MacCready (iD https://orcid.org/0000-0001-6438-8110

Pusparanee Hakim (iD https://orcid.org/0000-0002-9018-8179

Eric J Young (iD) https://orcid.org/0000-0002-6770-6310

Katherine W Osteryoung (iD) http://orcid.org/0000-0002-0028-2509

Anthony G Vecchiarelli (iD) https://orcid.org/0000-0002-6198-3245

Daniel C Ducat (iD) https://orcid.org/0000-0002-1520-0588

Decision letter and Author response

Decision letter https://doi.org/10.7554/eLife.39723.031

Author response https://doi.org/10.7554/eLife.39723.032

\section{Additional files}

Supplementary files

- Transparent reporting form

DOI: https://doi.org/10.7554/eLife.39723.027

Data availability

All data generated or analysed during this study are included in the manuscript and supporting files. Source data files have been provided for Figure 1-figure supplement 1 and Figure 2-figure supplement 1.

\section{References}

Adachi S, Hori K, Hiraga S. 2006. Subcellular positioning of F plasmid mediated by dynamic localization of SopA and SopB. Journal of Molecular Biology 356:850-863. DOI: https://doi.org/10.1016/j.jmb.2005.11.088, PMID: 16403518

Ah-Seng Y, Lopez F, Pasta F, Lane D, Bouet JY. 2009. Dual role of DNA in regulating ATP hydrolysis by the SopA partition protein. Journal of Biological Chemistry 284:30067-30075. DOI: https://doi.org/10.1074/jbc.M109. 044800, PMID: 19740757

Alvarado A, Kjær A, Yang W, Mann P, Briegel A, Waldor MK, Ringgaard S. 2017. Coupling chemosensory array formation and localization. eLife 6:e31058. DOI: https://doi.org/10.7554/eLife.31058, PMID: 29058677

Atmakuri K, Cascales E, Burton OT, Banta LM, Christie PJ. 2007. Agrobacterium ParA/MinD-like VirC1 spatially coordinates early conjugative DNA transfer reactions. The EMBO Journal 26:2540-2551. DOI: https://doi.org/ 10.1038/sj.emboj.7601696, PMID: 17505518

Axen SD, Erbilgin O, Kerfeld CA. 2014. A taxonomy of bacterial microcompartment loci constructed by a novel scoring method. PLoS Computational Biology 10:e1003898. DOl: https://doi.org/10.1371/journal.pcbi. 1003898, PMID: 25340524

Baxter JC, Funnell BE. 2014. Plasmid partition mechanisms. Microbiology Spectrum 2. DOI: https://doi.org/10. 1128/microbiolspec.PLAS-0023-2014, PMID: 26104442

Bouet JY, Funnell BE. 1999. P1 ParA interacts with the P1 partition complex at parS and an ATP-ADP switch controls ParA activities. The EMBO Journal 18:1415-1424. DOI: https://doi.org/10.1093/emboj/18.5.1415, PMID: 10064607

Bouet JY, Surtees JA, Funnell BE. 2000. Stoichiometry of P1 plasmid partition complexes. Journal of Biological Chemistry 275:8213-8219. DOI: https://doi.org/10.1074/jbc.275.11.8213, PMID: 10713146

Cai F, Sutter M, Cameron JC, Stanley DN, Kinney JN, Kerfeld CA. 2013. The structure of CcmP, a tandem bacterial microcompartment domain protein from the $\beta$-carboxysome, forms a subcompartment within a microcompartment. Journal of Biological Chemistry 288:16055-16063. DOI: https://doi.org/10.1074/jbc.M113. 456897, PMID: 23572529 
Cai F, Sutter M, Bernstein SL, Kinney JN, Kerfeld CA. 2015. Engineering bacterial microcompartment shells: chimeric shell proteins and chimeric carboxysome shells. ACS Synthetic Biology 4:444-453. DOI: https://doi. org/10.1021/sb500226j

Cameron JC, Wilson SC, Bernstein SL, Kerfeld CA. 2013. Biogenesis of a bacterial organelle: the carboxysome assembly pathway. Cell 155:1131-1140. DOI: https://doi.org/10.1016/j.cell.2013.10.044, PMID: 24267892

Castaing JP, Bouet JY, Lane D. 2008. F plasmid partition depends on interaction of SopA with non-specific DNA. Molecular Microbiology 70:1000-1011. DOI: https://doi.org/10.1111/j.1365-2958.2008.06465.x, PMID: 1 8826408

Chen AH, Robinson-Mosher A, Savage DF, Silver PA, Polka JK. 2013. The bacterial carbon-fixing organelle is formed by shell envelopment of preassembled cargo. PLoS ONE 8:e76127. DOI: https://doi.org/10.1371/ journal.pone.0076127, PMID: 24023971

Clerico EM, Ditty JL, Golden SS. 2007. Specialized techniques for site-directed mutagenesis in cyanobacteria. Methods in Molecular Biology 362:155-171. DOI: https://doi.org/10.1007/978-1-59745-257-1_11, PMID: 17417008

Cot SS, So AK, Espie GS. 2008. A multiprotein bicarbonate dehydration complex essential to carboxysome function in cyanobacteria. Journal of Bacteriology 190:936-945. DOI: https://doi.org/10.1128/JB.01283-07, PMID: 17993516

Davis MA, Austin SJ. 1988. Recognition of the P1 plasmid centromere analog involves binding of the ParB protein and is modified by a specific host factor. The EMBO Journal 7:1881-1888. DOI: https://doi.org/10. 1002/j.1460-2075.1988.tb03021.x, PMID: 3049080

Davis MA, Martin KA, Austin SJ. 1992. Biochemical activities of the parA partition protein of the P1 plasmid. Molecular Microbiology 6:1141-1147. DOI: https://doi.org/10.1111/j.1365-2958.1992.tb01552.x, PMID: 1534133

Drozdetskiy A, Cole C, Procter J, Barton GJ. 2015. JPred4: a protein secondary structure prediction server. Nucleic Acids Research 43:W389-W394. DOI: https://doi.org/10.1093/nar/gkv332, PMID: 25883141

Ducret A, Quardokus EM, Brun YV. 2016. MicrobeJ, a tool for high throughput bacterial cell detection and quantitative analysis. Nature Microbiology 1:16077. DOI: https://doi.org/10.1038/nmicrobiol.2016.77, PMID: 27572972

Fan C, Cheng S, Sinha S, Bobik TA. 2012. Interactions between the termini of lumen enzymes and shell proteins mediate enzyme encapsulation into bacterial microcompartments. PNAS 109:14995-15000. DOI: https://doi. org/10.1073/pnas.1207516109, PMID: 22927404

Fange D, Elf J. 2006. Noise-induced Min phenotypes in E. coli. PLoS Computational Biology 2:e80. DOI: https:// doi.org/10.1371/journal.pcbi.0020080, PMID: 16846247

Faulkner M, Rodriguez-Ramos J, Dykes GF, Owen SV, Casella S, Simpson DM, Beynon RJ, Liu LN. 2017. Direct characterization of the native structure and mechanics of cyanobacterial carboxysomes. Nanoscale 9:1066210673. DOI: https://doi.org/10.1039/C7NR02524F, PMID: 28616951

Fung E, Bouet JY, Funnell BE. 2001. Probing the ATP-binding site of P1 ParA: partition and repression have different requirements for ATP binding and hydrolysis. The EMBO Journal 20:4901-4911. DOI: https://doi.org/ 10.1093/emboj/20.17.4901, PMID: 11532954

Funnell BE. 1988. Mini-P1 plasmid partitioning: excess ParB protein destabilizes plasmids containing the centromere parS. Journal of Bacteriology 170:954-960. DOI: https://doi.org/10.1128/jb.170.2.954-960.1988, PMID: 2962991

Gibson DG, Young L, Chuang RY, Venter JC, Hutchison CA, Smith HO. 2009. Enzymatic assembly of DNA molecules up to several hundred kilobases. Nature Methods 6:343-345. DOI: https://doi.org/10.1038/nmeth. 1318, PMID: 19363495

Hatano T, Yamaichi Y, Niki H. 2007. Oscillating focus of SopA associated with filamentous structure guides partitioning of F plasmid. Molecular Microbiology 64:1198-1213. DOI: https://doi.org/10.1111/j.1365-2958. 2007.05728.x, PMID: 17542915

Hatano T, Niki H. 2010. Partitioning of P1 plasmids by gradual distribution of the ATPase ParA. Molecular Microbiology 78:1182-1198. DOI: https://doi.org/10.1111/j.1365-2958.2010.07398.x, PMID: 21091504

Hester CM, Lutkenhaus J. 2007. Soj (ParA) DNA binding is mediated by conserved arginines and is essential for plasmid segregation. PNAS 104:20326-20331. DOI: https://doi.org/10.1073/pnas.0705196105, PMID: 180773 87

Hu B, Yang G, Zhao W, Zhang Y, Zhao J. 2007. MreB is important for cell shape but not for chromosome segregation of the filamentous cyanobacterium Anabaena sp. PCC 7120. Molecular Microbiology 63:16401652. DOI: https://doi.org/10.1111/j.1365-2958.2007.05618.x, PMID: 17367385

Hu L, Vecchiarelli AG, Mizuuchi K, Neuman KC, Liu J. 2015. Directed and persistent movement arises from mechanochemistry of the ParA/ParB system. PNAS 112:E7055-E7064. DOI: https://doi.org/10.1073/pnas. 1505147112, PMID: 26647183

Hu L, Vecchiarelli AG, Mizuuchi K, Neuman KC, Liu J. 2017. Brownian ratchet mechanism for faithful segregation of low-copy-number plasmids. Biophysical Journal 112:1489-1502. DOI: https://doi.org/10.1016/j.bpj.2017.02. 039, PMID: 28402891

Hwang LC, Vecchiarelli AG, Han YW, Mizuuchi M, Harada Y, Funnell BE, Mizuuchi K. 2013. ParA-mediated plasmid partition driven by protein pattern self-organization. The EMBO Journal 32:1238-1249. DOI: https:// doi.org/10.1038/emboj.2013.34, PMID: 23443047 
Jordan A, Chandler J, MacCready JS, Huang J, Osteryoung KW, Ducat DC. 2017. Engineering cyanobacterial cell morphology for enhanced recovery and processing of biomass. Applied and Environmental Microbiology 83: e00053-17. DOI: https://doi.org/10.1128/AEM.00053-17, PMID: 28235875

Karimova G, Pidoux J, Ullmann A, Ladant D. 1998. A bacterial two-hybrid system based on a reconstituted signal transduction pathway. PNAS 95:5752-5756. DOI: https://doi.org/10.1073/pnas.95.10.5752, PMID: 9576956

Kelley LA, Mezulis S, Yates CM, Wass MN, Sternberg MJ. 2015. The Phyre2 web portal for protein modeling, prediction and analysis. Nature Protocols 10:845-858. DOI: https://doi.org/10.1038/nprot.2015.053, PMID: 25 950237

Kerfeld CA, Sawaya MR, Tanaka S, Nguyen CV, Phillips M, Beeby M, Yeates TO. 2005. Protein structures forming the shell of primitive bacterial organelles. Science 309:936-938. DOI: https://doi.org/10.1126/science. 1113397, PMID: 16081736

Kerfeld CA, Erbilgin O. 2015. Bacterial microcompartments and the modular construction of microbial metabolism. Trends in Microbiology 23:22-34. DOI: https://doi.org/10.1016/j.tim.2014.10.003

Kerfeld CA, Melnicki MR. 2016. Assembly, function and evolution of cyanobacterial carboxysomes. Current Opinion in Plant Biology 31:66-75. DOI: https://doi.org/10.1016/j.pbi.2016.03.009, PMID: 27060669

Kinney JN, Salmeen A, Cai F, Kerfeld CA. 2012. Elucidating essential role of conserved carboxysomal protein $\mathrm{CcmN}$ reveals common feature of bacterial microcompartment assembly. Journal of Biological Chemistry 287: 17729-17736. DOI: https://doi.org/10.1074/jbc.M112.355305, PMID: 22461622

Kusumoto A, Shinohara A, Terashima H, Kojima S, Yakushi T, Homma M. 2008. Collaboration of FlhF and FlhG to regulate polar-flagella number and localization in Vibrio alginolyticus. Microbiology 154:1390-1399. DOI: https://doi.org/10.1099/mic.0.2007/012641-0, PMID: 18451048

Lasocki K, Bartosik AA, Mierzejewska J, Thomas CM, Jagura-Burdzy G. 2007. Deletion of the parA (soj) homologue in pseudomonas aeruginosa causes ParB instability and affects growth rate, chromosome segregation, and motility. Journal of Bacteriology 189:5762-5772. DOI: https://doi.org/10.1128/JB.00371-07

Le Gall A, Cattoni DI, Guilhas B, Mathieu-Demazière C, Oudjedi L, Fiche JB, Rech J, Abrahamsson S, Murray H, Bouet JY, Nollmann M. 2016. Bacterial partition complexes segregate within the volume of the nucleoid. Nature Communications 7:12107. DOI: https://doi.org/10.1038/ncomms12107, PMID: 27377966

Leonard TA, Butler PJ, Löwe J. 2005. Bacterial chromosome segregation: structure and DNA binding of the Soj dimer-a conserved biological switch. The EMBO Journal 24:270-282. DOI: https://doi.org/10.1038/sj.emboj. 7600530, PMID: 15635448

Lim HC, Surovtsev IV, Beltran BG, Huang F, Bewersdorf J, Jacobs-Wagner C. 2014. Evidence for a DNA-relay mechanism in ParABS-mediated chromosome segregation. eLife 3:e02758. DOI: https://doi.org/10.7554/eLife. 02758, PMID: 24859756

Long BM, Badger MR, Whitney SM, Price GD. 2007. Analysis of carboxysomes from Synechococcus PCC7942 reveals multiple Rubisco complexes with carboxysomal proteins CcmM and CcaA. Journal of Biological Chemistry 282:29323-29335. DOI: https://doi.org/10.1074/jbc.M703896200, PMID: 17675289

Long BM, Tucker L, Badger MR, Price GD. 2010. Functional cyanobacterial beta-carboxysomes have an absolute requirement for both long and short forms of the CcmM protein. Plant Physiology 153:285-293. DOI: https:// doi.org/10.1104/pp.110.154948, PMID: 20304968

Loose M, Fischer-Friedrich E, Ries J, Kruse K, Schwille P. 2008. Spatial regulators for bacterial cell division selforganize into surface waves in vitro. Science 320:789-792. DOl: https://doi.org/10.1126/science.1154413, PMID: 18467587

Loose M, Kruse K, Schwille P. 2011. Protein self-organization: lessons from the min system. Annual Review of Biophysics 40:315-336. DOI: https://doi.org/10.1146/annurev-biophys-042910-155332, PMID: 21545286

Lutkenhaus J. 2007. Assembly dynamics of the bacterial MinCDE system and spatial regulation of the $Z$ ring. Annual Review of Biochemistry 76:539-562. DOI: https://doi.org/10.1146/annurev.biochem.75.103004.142652, PMID: 17328675

Lutkenhaus J. 2012. The ParA/MinD family puts things in their place. Trends in Microbiology 20:411-418. DOI: https://doi.org/10.1016/j.tim.2012.05.002, PMID: 22672910

MacCready JS, Schossau J, Osteryoung KW, Ducat DC. 2017. Robust Min-system oscillation in the presence of internal photosynthetic membranes in cyanobacteria. Molecular Microbiology 103:483-503. DOI: https://doi. org/10.1111/mmi.13571, PMID: 27891682

Miyagishima SY, Wolk CP, Osteryoung KW. 2005. Identification of cyanobacterial cell division genes by comparative and mutational analyses. Molecular Microbiology 56:126-143. DOI: https://doi.org/10.1111/j. 1365-2958.2005.04548.x, PMID: 15773984

Montgomery BL. 2015. Light-dependent governance of cell shape dimensions in cyanobacteria. Frontiers in Microbiology 6:514. DOI: https://doi.org/10.3389/fmicb.2015.00514, PMID: 26074902

Murat D, Byrne M, Komeili A. 2010. Cell biology of prokaryotic organelles. Cold Spring Harbor Perspectives in Biology 2:a000422. DOI: https://doi.org/10.1101/cshperspect.a000422, PMID: 20739411

Murata K, Hagiwara S, Kimori Y, Kaneko Y. 2016. Ultrastructure of compacted DNA in cyanobacteria by highvoltage cryo-electron tomography. Scientific Reports 6:34934. DOI: https://doi.org/10.1038/srep34934, PMID: 27731339

Nakahira Y, Ogawa A, Asano H, Oyama T, Tozawa Y. 2013. Theophylline-dependent riboswitch as a novel genetic tool for strict regulation of protein expression in Cyanobacterium Synechococcus elongatus PCC 7942. Plant and Cell Physiology 54:1724-1735. DOI: https://doi.org/10.1093/pcp/pct115, PMID: 23969558 
Parsons JB, Frank S, Bhella D, Liang M, Prentice MB, Mulvihill DP, Warren MJ. 2010. Synthesis of empty bacterial microcompartments, directed organelle protein incorporation, and evidence of filament-associated organelle movement. Molecular Cell 38:305-315. DOI: https://doi.org/10.1016/j.molcel.2010.04.008, PMID: 20417607

Perez-Cheeks BA, Planet PJ, Sarkar IN, Clock SA, Xu Q, Figurski DH. 2012. The product of tadZ, a new member of the parA/minD superfamily, localizes to a pole in Aggregatibacter actinomycetemcomitans. Molecular Microbiology 83:694-711. DOI: https://doi.org/10.1111/j.1365-2958.2011.07955.x, PMID: 22239271

Price GD, Badger MR. 1989. Isolation and characterization of high CO(2)-Requiring-Mutants of the cyanobacterium synechococcus PCC7942 : two phenotypes that accumulate inorganic carbon but are apparently unable to generate CO(2) within the carboxysome. Plant Physiology 91:514-525. DOI: https://doi. org/10.1104/pp.91.2.514, PMID: 16667063

Price GD, Howitt SM, Harrison K, Badger MR. 1993. Analysis of a genomic DNA region from the cyanobacterium Synechococcus sp. strain PCC7942 involved in carboxysome assembly and function. Journal of Bacteriology 175:2871-2879. DOI: https://doi.org/10.1128/jb.175.10.2871-2879.1993, PMID: 8491708

Ptacin JL, Lee SF, Garner EC, Toro E, Eckart M, Comolli LR, Moerner WE, Shapiro L. 2010. A spindle-like apparatus guides bacterial chromosome segregation. Nature Cell Biology 12:791-798. DOI: https://doi.org/10. 1038/ncb2083, PMID: 20657594

Rae BD, Long BM, Badger MR, Price GD. 2012. Structural determinants of the outer shell of $\beta$-carboxysomes in Synechococcus elongatus PCC 7942: roles for CcmK2, K3-K4, CcmO, and CcmL. PLoS ONE 7:e43871. DOI: https://doi.org/10.1371/journal.pone.0043871, PMID: 22928045

Rae BD, Long BM, Badger MR, Price GD. 2013. Functions, compositions, and evolution of the two types of carboxysomes: polyhedral microcompartments that facilitate $\mathrm{CO} 2$ fixation in cyanobacteria and some proteobacteria. Microbiology and Molecular Biology Reviews 77:357-379. DOI: https://doi.org/10.1128/ MMBR.00061-12, PMID: 24006469

Ringgaard S, van Zon J, Howard M, Gerdes K. 2009. Movement and equipositioning of plasmids by ParA filament disassembly. PNAS 106:19369-19374. DOI: https://doi.org/10.1073/pnas.0908347106, PMID: 19906 997

Ringgaard S, Schirner K, Davis BM, Waldor MK. 2011. A family of ParA-like ATPases promotes cell pole maturation by facilitating polar localization of chemotaxis proteins. Genes \& Development 25:1544-1555. DOI: https://doi.org/10.1101/gad.2061811, PMID: 21764856

Savage DF, Afonso B, Chen AH, Silver PA. 2010. Spatially ordered dynamics of the bacterial carbon fixation machinery. Science 327:1258-1261. DOI: https://doi.org/10.1126/science.1186090, PMID: 20203050

Schofield WB, Lim HC, Jacobs-Wagner C. 2010. Cell cycle coordination and regulation of bacterial chromosome segregation dynamics by polarly localized proteins. The EMBO Journal 29:3068-3081. DOI: https://doi.org/10. 1038/emboj.2010.207, PMID: 20802464

Sengupta M, Nielsen HJ, Youngren B, Austin S. 2010. P1 plasmid segregation: accurate redistribution by dynamic plasmid pairing and separation. Journal of Bacteriology 192:1175-1183. DOI: https://doi.org/10.1128/ JB.01245-09, PMID: 19897644

Sommer M, Cai F, Melnicki M, Kerfeld CA. 2017. $\beta$-Carboxysome bioinformatics: identification and evolution of new bacterial microcompartment protein gene classes and core locus constraints. Journal of Experimental Botany 68:3841-3855. DOI: https://doi.org/10.1093/jxb/erx115, PMID: 28419380

Sun Y, Casella S, Fang Y, Huang F, Faulkner M, Barrett S, Liu LN. 2016. Light modulates the biosynthesis and organization of cyanobacterial carbon fixation machinery through photosynthetic electron flow. Plant Physiology 171:530-541. DOI: https://doi.org/10.1104/pp.16.00107, PMID: 26956667

Surovtsev IV, Campos M, Jacobs-Wagner C. 2016. DNA-relay mechanism is sufficient to explain ParAdependent intracellular transport and patterning of single and multiple cargos. PNAS 113:E7268-E7276. DOI: https://doi.org/10.1073/pnas.1616118113, PMID: 27799522

Tanaka S, Kerfeld CA, Sawaya MR, Cai F, Heinhorst S, Cannon GC, Yeates TO. 2008. Atomic-level models of the bacterial carboxysome shell. Science 319:1083-1086. DOI: https://doi.org/10.1126/science.1151458, PMID: 1 8292340

Tanaka S, Sawaya MR, Phillips M, Yeates TO. 2009. Insights from multiple structures of the shell proteins from the beta-carboxysome. Protein Science : A Publication of the Protein Society 18:108-120. DOI: https://doi.org/ 10.1002/pro.14, PMID: 19177356

Thompson SR, Wadhams GH, Armitage JP. 2006. The positioning of cytoplasmic protein clusters in bacteria. PNAS 103:8209-8214. DOI: https://doi.org/10.1073/pnas.0600919103, PMID: 16702547

Vecchiarelli AG, Han YW, Tan X, Mizuuchi M, Ghirlando R, Biertümpfel C, Funnell BE, Mizuuchi K. 2010. ATP control of dynamic P1 ParA-DNA interactions: a key role for the nucleoid in plasmid partition. Molecular Microbiology 78:78-91. DOI: https://doi.org/10.1111/j.1365-2958.2010.07314.x, PMID: 20659294

Vecchiarelli AG, Mizuuchi K, Funnell BE. 2012. Surfing biological surfaces: exploiting the nucleoid for partition and transport in bacteria. Molecular Microbiology 86:513-523. DOI: https://doi.org/10.1111/mmi.12017, PMID: 22934804

Vecchiarelli AG, Hwang LC, Mizuuchi K. 2013. Cell-free study of F plasmid partition provides evidence for cargo transport by a diffusion-ratchet mechanism. PNAS 110:E1390-E1397. DOI: https://doi.org/10.1073/pnas. 1302745110, PMID: 23479605

Vecchiarelli AG, Neuman KC, Mizuuchi K. 2014. A propagating ATPase gradient drives transport of surfaceconfined cellular cargo. PNAS 111:4880-4885. DOI: https://doi.org/10.1073/pnas.1401025111, PMID: 24567408 
Vecchiarelli AG, Li M, Mizuuchi M, Hwang LC, Seol Y, Neuman KC, Mizuuchi K. 2016. Membrane-bound MinDE complex acts as a toggle switch that drives Min oscillation coupled to cytoplasmic depletion of MinD. PNAS 113:E1479-E1488. DOI: https://doi.org/10.1073/pnas.1600644113, PMID: 26884160

Viollier PH, Sternheim N, Shapiro L. 2002. A dynamically localized histidine kinase controls the asymmetric distribution of polar pili proteins. The EMBO Journal 21:4420-4428. DOI: https://doi.org/10.1093/emboj/ cdf454, PMID: 12198144

Wagstaff J, Löwe J. 2018. Prokaryotic cytoskeletons: protein filaments organizing small cells. Nature Reviews Microbiology 16:187-201. DOI: https://doi.org/10.1038/nrmicro.2017.153, PMID: 29355854

Yokoo R, Hood RD, Savage DF. 2015. Live-cell imaging of cyanobacteria. Photosynthesis Research 126:33-46. DOI: https://doi.org/10.1007/s11120-014-0049-x, PMID: 25366827

Youderian P, Burke N, White DJ, Hartzell PL. 2003. Identification of genes required for adventurous gliding motility in Myxococcus xanthus with the transposable element mariner. Molecular Microbiology 49:555-570. DOI: https://doi.org/10.1046/j.1365-2958.2003.03582.x, PMID: 12828649

Young EJ, Burton R, Mahalik JP, Sumpter BG, Fuentes-Cabrera M, Kerfeld CA, Ducat DC. 2017. Engineering the bacterial microcompartment domain for molecular scaffolding applications. Frontiers in Microbiology 8:1441. DOI: https://doi.org/10.3389/fmicb.2017.01441, PMID: 28824573

Zhang H, Schumacher MA. 2017. Structures of partition protein ParA with nonspecific DNA and ParB effector reveal molecular insights into principles governing Walker-box DNA segregation. Genes \& Development 31: 481-492. DOI: https://doi.org/10.1101/gad.296319.117, PMID: 28373206

Zieske K, Schwille P. 2014. Reconstitution of self-organizing protein gradients as spatial cues in cell-free systems. elife 3:e03949. DOI: https://doi.org/10.7554/eLife.03949 